\title{
Data-adaptive spatio-temporal filtering of GRACE data
}

\author{
Paoline Prevost ${ }^{\oplus},{ }^{1,2}$ Kristel Chanard, ${ }^{3}$ Luce Fleitout, ${ }^{1}$ Eric Calais, ${ }^{1}$ Damian Walwer,,${ }^{1,4}$ \\ Tonie van Dam ${ }^{2}$ and Michael Ghil ${ }^{5,6}$ \\ ${ }^{1}$ Laboratoire de Géologie, École Normale Supérieure, Université PSL, CNRS UMR 8538, Paris, France. E-mail: prevost@geologie.ens.fr \\ ${ }^{2}$ University of Luxembourg, Esch-sur-Alzette, Luxembourg \\ ${ }^{3} I P G P$, IGN, Université Paris Diderot, Sorbonne Paris Cité, UMR 7154 CNRS, Paris, France \\ ${ }^{4}$ Laboratoire de Géologie, Terre, Planète, Environnement, École Normale Supérieure de Lyon, Lyon, France \\ ${ }^{5}$ Geosciences Department, École Normale Supérieure, Université PSL, Paris, France \\ ${ }^{6}$ Department of Atmospheric \& Oceanic Sciences, University of California, Los Angeles, CA, USA
}

Accepted 2019 September 19. Received 2019 September 5; in original form 2018 November 21

\begin{abstract}
SUMMAR Y
Measurements of the spatio-temporal variations of Earth's gravity field from the Gravity Recovery and Climate Experiment (GRACE) mission have led to new insights into large spatial mass redistribution at secular, seasonal and subseasonal timescales. GRACE solutions from various processing centres, while adopting different processing strategies, result in rather coherent estimates. However, these solutions also exhibit random as well as systematic errors, with specific spatial patterns in the latter.

In order to dampen the noise and enhance the geophysical signals in the GRACE data, we propose an approach based on a data-driven spatio-temporal filter, namely the Multichannel Singular Spectrum Analysis (M-SSA). M-SSA is a data-adaptive, multivariate, and non-parametric method that simultaneously exploits the spatial and temporal correlations of geophysical fields to extract common modes of variability.

We perform an M-SSA analysis on 13 yr of GRACE spherical harmonics solutions from five different processing centres in a simultaneous setup. We show that the method allows us to extract common modes of variability between solutions, while removing solution-specific spatio-temporal errors that arise from the processing strategies. In particular, the method efficiently filters out the spurious north-south stripes, which are caused in all likelihood by aliasing, due to the imperfect geophysical correction models and low-frequency noise in measurements.

Comparison of the M-SSA GRACE solution with mass concentration (mascons) solutions shows that, while the former remains noisier, it does retrieve geophysical signals masked by the mascons regularization procedure.
\end{abstract}

Key words: Satellite gravity; Time variable gravity; Time-series analysis.

\section{INTRODUCTION}

The Gravity Recovery and Climate Experiment (GRACE) satellite mission has provided precise measurements of the spatio-temporal variations of the Earth gravity field from 2002 to 2017. These variations represent changes in mass primarily due to megathrust earthquakes, atmospheric, oceanic and continental water mass redistribution from monthly to decadal timescales, once well-modelled processes such as tides and glacial isostatic adjustment are accounted for (Tapley et al. 2004).

The GRACE mission has been used in many hydrological and geophysical studies over the past two decades. GRACE has, for example, provided new insights into total water storage variations (Ramillien et al. 2008; Cazenave \& Chen 2010), regional hydrological balance (Landerer et al. 2010), ice mass balance (Velicogna \& Wahr 2013), ocean water distribution (Chambers \& Bonin 2012), earthquake-produced gravity signals (Chen et al. 2007b; Panet et al. 2007) and polar wander (Adhikari \& Ivins 2016).

Although GRACE-based gravity maps have led to scientific advances in many geoscientific applications, they remain affected by errors in the raw observations and their processing that limit their precision (Kusche 2007; Flechtner et al. 2016). In particular, GRACE data are affected by both systematic and random noise. North-south stripes linked to the quasi-polar orbit of GRACE satellites are the most conspicuous spurious signal in the gravity maps. Indeed, since GRACE solutions are monthly averaged, they are affected by aliasing errors in tidal and non-tidal model corrections with periods ranging from hours to days (Han et al. 2004; Thompson et al. 2004; Seo et al. 2008). 
The geophysical signals in GRACE data are spatially and temporally correlated while these north-south spurious stripes present small-scale spatial correlation but no temporal correlation.

One way to reduce this noise in the monthly solutions is to regularize the spherical harmonics coefficients (SHs) that represent the GRACE Earth gravity field (Lemoine et al. 2007, 2013; Watkins et al. 2015). However, since the regularization scheme depends on the applications and needed spatial resolution (Kusche 2007; Kusche et al. 2009), the processing centres usually provide unconstrained solutions requiring post-processing. Post-processing methods include, for example, an isotropic Gaussian filter (Jekeli 1981; Schrama et al. 2007), a degree- and order-dependent filter (Swenson \& Wahr 2002; Guo et al. 2010), a time-dynamic filter (Seo et al. 2006) or decorrelation (Swenson \& Wahr 2006; Kusche 2007; Kusche et al. 2009). This two-step approach, though, causes spatial leakage errors induced by the SH truncation, as well as by the post-processing filters applied to the data (Chen et al. 2007a; Landerer \& Swenson 2012). Aliasing and leakage errors remain an important issue in using GRACE data, as they imply selecting the appropriate filter to keep a good spatial resolution while removing as much of the errors as possible in the solution.

A large effort has been made recently to develop methods limiting both leakage and aliasing effects in GRACE-based maps. One possibility to reduce noise in the GRACE data is to take the mean of the solutions obtained by different processing centres (Werth et al. 2009; Sakumura et al. 2014). Another more recent possibility is the use of mascon (mass concentration) solutions that reduce the leakage from land to ocean by applying geophysical constraints during the processing (Luthcke et al. 2013; Watkins et al. 2015; Save et al. 2016). However, mascon solutions use a priori information on the spatio-temporal pattern of these geophysical constraints that damp unexpected signals.

Alternatively, the task of isolating spatially and temporally correlated geophysical signals from random errors in geodetic time-series can be approached by applying a data-adaptive, multivariate and non-parametric method available due to recent developments in statistical signal-processing techniques. For instance, Multichannel Singular Spectrum Analysis (M-SSA: Ghil et al. 2002; Walwer et al. 2016) is well suited to extract common modes of spatio-temporal variability from geophysical time-series without a priori knowledge on the signals of interest or on the noise present in the time-series. Other component analysis methods, like principal component analysis (PCA) and independent component analysis (ICA) were used on GRACE data (Frappart et al. 2010; Forootan et al. 2012; Seoane et al. 2013). Contrary to them, M-SSA uses lag copies of the time-series which allows for the detection of temporal correlations in delayed signals. It also uses more components in the decomposition which allows for more flexibility in the different modes, especially for periodic signal represented by pair of components. M-SSA has previously been used to analyse GRACE time-series and proven to efficiently separate the oscillatory components with variable amplitude at annual and semi-annual periods from other signals (Rangelova et al. 2012). Contrary to previous work, in which M-SSA was used on an individual GRACE solution, here we apply the methodology directly to GRACE SHs from several processing centres to try to mitigate the effect of their individual errors.

In this paper, we combine GRACE solutions expressed in terms of SHs from five analysis centres and use M-SSA to isolate geophysical signals and minimize processing errors. This combination allows to use a filter which damps small wavelengths less than the commonly used filters. After describing in Section 2 the GRACE data used in this study, we introduce briefly the M-SSA method in Section 3 and describe the procedure that we have used to clean up the GRACE data set and test it out on synthetic data set and hydrological model. In Section 4.1, we then compare this M-SSA GRACE solution with published SHs and mascon solutions, and discuss advantages and drawbacks of this method. Finally, in Sections 4.2 and 4.3, we assess the performance of this M-SSA GRACE solution by focusing on regional examples, namely the Caspian and Aral seas, continental hydrological basins, subduction zones and the Lake Nasser area.

\section{GRACE LEVEL-2 SOLUTIONS}

The GRACE satellite mission, launched in 2002 and decommissioned in 2017, has provided maps of the Earth's gravity field with a spatial resolution of a few hundred kilometres and a temporal resolution of 1 month (Bettadpur 2012; Watkins \& Yuan 2012; Dahle et al. 2013; Mayer-Gürr et al. 2016) to $10 \mathrm{~d}$ (Tapley et al. 2004; Lemoine et al. 2013). Several processing centres have released constrained and/or unconstrained solutions in terms of SHs (Wahr et al. 1998) and surface mass density grids usually expressed in equivalent water height (EWH) with a given water density. Although processing strategies differ, solutions are consistent within $\pm 50 \mathrm{~mm}$ EWH, but also exhibit both systematic and random noise (Sakumura et al. 2014). The raw GRACE data are called Level-1, while the processed data are called Level-2.

In this study, we use monthly solutions expressed in SHs from five analysis centres for which specifications are given in Table 1; these centres are listed below:

(1) CSR - the Centre for Space Research of the University of Texas;

(2) GFZ - the German Research Centre for Geosciences;

(3) GRAZ - the Institute of Geodesy of the University of Graz;

(4) JPL - NASA's Jet Propulsion Laboratory and

(5) GRGS - the French Research Group for Spatial Geodesy.

Four of the gravity solutions in Table 1, namely (1)-(4), are unconstrained. We also use the regularized solution (5) but apply the same post-processing filters to all five solutions for consistency. Note also that solution (5) is based on a de-aliasing approach different from that of solutions (1)-(4), as described in Table 1.

The noise is huge in unconstrained solutions and our attempts to proceed directly, that is without pre-filtering these solutions, were unsuccessful. We decided then to apply a filter to all the solutions. To filter and destripe the GRACE solutions used in this study, we adopt 
Table 1. GRACE data sets used in this study, with the truncation degree of the spherical harmonics $(\mathrm{SH})$ decomposition, the starting and ending dates of data availability for each solution, and the dealiasing models used for the atmosphere and ocean masses. A0D1B is the Atmosphere and Ocean De-aliasing Level-1B model developed by the GFZ (Flechtner et al. 2013), TUGO is the Toulouse Unstructured Grid Ocean model (Lyard 2010), and ERAInterim is a reanalysis of the global atmosphere using a fixed version of the European Centre for Medium-Range Weather Forecasts (ECMWF) atmospheric model and data assimilation method, along with atmospheric observations that start in 1979 (Dee et al. 2011).

\begin{tabular}{lcccccc}
\hline$\#$ & Centre & Version & Max. deg. & Start & End & Dealiasing \\
\hline 1 & CSR & RL05 & 90 & $04 / 2002$ & $06 / 2017$ & AOD1B RL05 \\
2 & GFZ & RL05a & 90 & $04 / 2002$ & $12 / 2016$ & AOD1B RL05 \\
3 & GRAZ & ITSG2016 & 90 & $04 / 2002$ & $12 / 2016$ & AOD1B RL05 \\
4 & JPL & RL05 & 60 & $04 / 2002$ & $06 / 2017$ & AOD1B RL05 \\
5 & GRGS & RL03 & 80 & $08 / 2002$ & $05 / 2016$ & ERA-Interim and TUGO \\
\hline
\end{tabular}

first the widely used DDK filter (Kusche 2007; Kusche et al. 2009). DDK is a non-isotropic decorrelation filter based on a regularization of the normal equation; it uses a priori error covariance matrices derived from GRACE processing. The DDK filter offers several levels of smoothing, with DDK1 being the strongest one, and DDK8 the weakest. As the smoothing intensity decreases, the geophysical signal is better preserved but the errors become larger and manifest themselves mainly as north-south stripes.

For geophysical applications, the processing centres recommend an average of solutions from the official processing centres (CSR, GFZ and JPL), to which the DDK5 spatial filter has been applied (Sakumura et al. 2014). This recommendation is meant to insure a good compromise between signal retained and noise removed. Fig. 1(a) shows, as an example, the mean of GRACE mass anomaly DDK5-filtered solutions from CSR, GFZ and JPL for the month of January 2006, relative to July 2005. Fig. 1(b) presents, for the same period, the mean of the data provided by all five centres used in this study, filtered with the weaker DDK7 filter. Similar maps are given for each of the five solutions used in this study in Fig. S1.

The variations recorded by the mean, DDK5-filtered GRACE solution over a 6-month interval exhibits north-south stripes characteristic of the error pattern of the GRACE data. Also visible are larger scale geophysical signals that correspond to known large annual hydrological variations, in the Amazon basin or Southeast Asia, for example. Maps of mean mass rates from January 2003 to December 2014 for the official solution, based on the mean of the three official centres, are provided in Fig. S2.

In this study, in order to more accurately locate geophysical signals in the GRACE solutions, we apply the DDK7 filter, with a weaker degree of filtering than DDK5, to all five Level-2 GRACE solutions.

\section{METHODOLOGY AND RESULTS}

\subsection{Multichannel singular spectrum analysis (M-SSA)}

Starting from GRACE Level-2 solutions, post-processed with the DDK7 filter, we developed a methodology that is as objective as possiblethat is, that makes use of the smallest amount of a priori information - to preserve geophysical signals while removing the spurious random and processing noise. As the GRACE data set exhibits correlations in both time and space, we adopt a data-adaptive method that simultaneously exploits these correlations, namely the M-SSA (Vautard \& Ghil 1989; Ghil \& Vautard 1991; Vautard et al. 1992; Ghil et al. 2002; Alessio 2016, ch. 12). The Singular Spectrum is the spectrum of singular values, which equal the square roots of the eigenvalues of a covariance matrix, and are obtained by singular-value decomposition of the matrix. The term Multichannel or, alternatively, Multivariate refers to the simultaneous use of several time-series.

We present here the general M-SSA methodology which will be applied twice hereafter, first on an ensemble of time-series consisting of the coefficients from the five centres for a given spherical harmonic (see Section 3.2), and second on the EWH time-series at seven given points (see Section 3.3).

M-SSA extracts from the data a set of empirical orthogonal functions (EOFs) representing the common spatio-temporal modes of variability of the time-series being analysed (Ghil et al. 2002; Walwer et al. 2016, and references therein). The M-SSA and its advantages over other usual methods like univariate SSA or PCA are well described by Walwer et al. (2016). The time-series one wants to study can then be projected onto these EOFs, and thus provide a decomposition into components that correspond either to trends with variable slope, oscillations or noise. Because the EOFs are directly deduced from the data, the M-SSA does not require a priori information on the spatio-temporal characteristics of the time-series.

Let us take an ensemble of $L$ time-series

$\left\{\mathbf{X}_{l}(t): l=1, \ldots, L ; t=1, \ldots, N\right\}$,

$N$ being the number of data points in each. In the cases treated here, all the time-series need to have the same constant sampling interval $\Delta t$.

The main idea of M-SSA is to exploit the covariance information contained in series of $M$ lagged copies of all the $\mathbf{X}_{l}(t)$ 's (Ghil et al. 2002; Walwer et al. 2016). The choice of the window length $M$ must be made according to the data set to optimize the quantity of information 

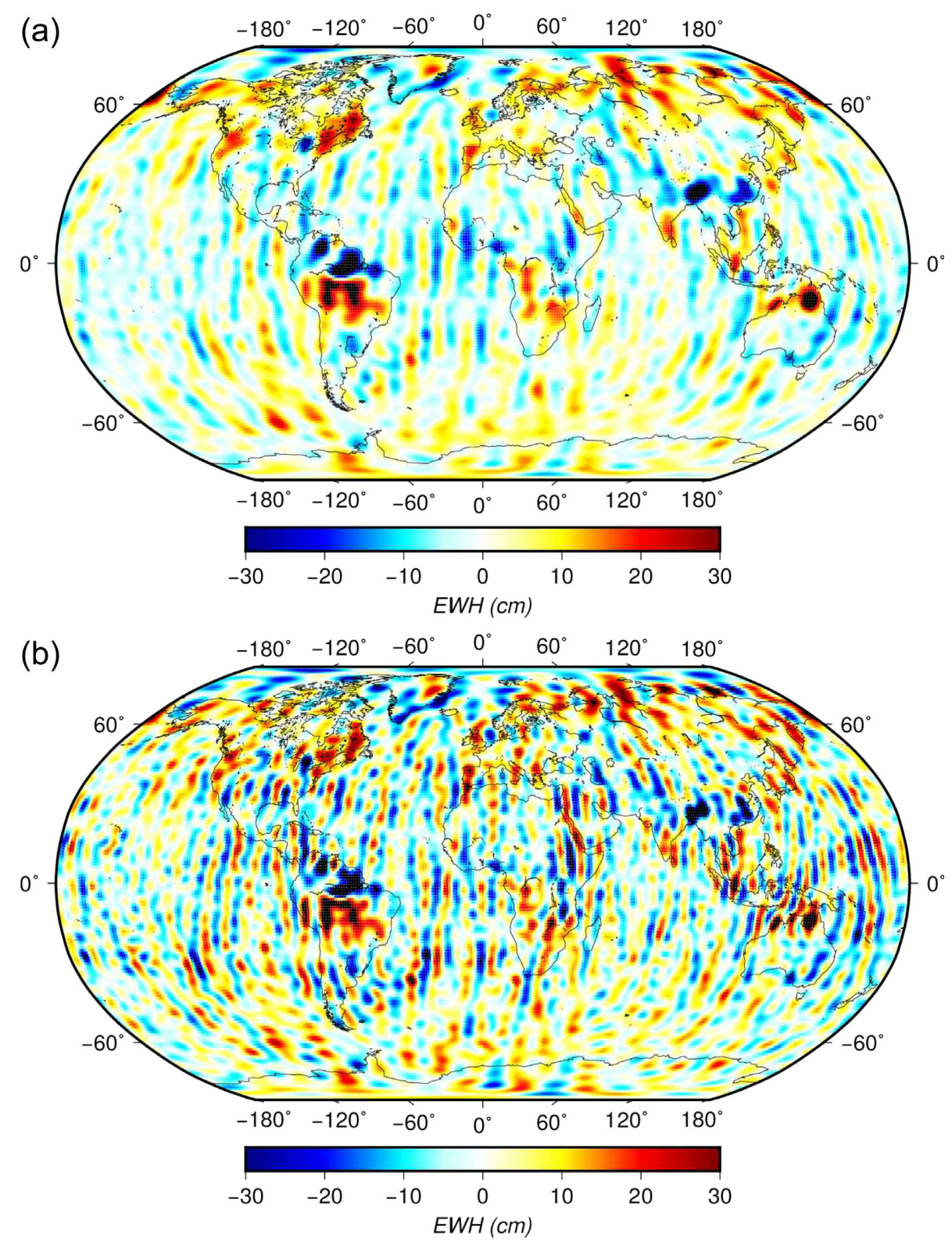

Figure 1. Surface mass density anomaly solutions for January 2006, relative to July 2005, expressed in equivalent water height (EWH, in $\mathrm{cm}$ ): (a) mean of CSR, GFZ and JPL solutions derived from GRACE and filtered using the decorrelation filter DDK5 and (b) mean of CSR, GFZ, GRAZ, GRGS and JPL solutions filtered with DDK7.

extracted, while maintaining satisfactory statistical confidence. On the one hand, increasing $M$ allows to discriminate signals with larger periods because the elementary extracted EOF have a length equal to $M * \Delta T$. On the other hand, larger $M$ leads to lower values for the ratio $N / M$ which implies lower statistical significance of the signals extracted with the M-SSA.

We start by constructing the matrix $\widetilde{\mathbf{X}}_{l}$ that includes $M$ time-delayed copies of the original time-series $\mathbf{X}_{l}(t)$ as its columns:

$\widetilde{\mathbf{X}}_{l}=\left(\begin{array}{cccc}\mathbf{X}_{\mathbf{l}}(\mathbf{1}) & \mathbf{X}_{l}(2) & \ldots & \mathbf{X}_{l}(M) \\ \mathbf{X}_{l}(2) & \mathbf{X}_{l}(3) & \cdots & \mathbf{X}_{l}(M+1) \\ \cdot & \cdot & \cdots & \cdot \\ \cdot & \cdot & \cdots & \cdot \\ \mathbf{X}_{l}\left(N^{\prime}\right) & \mathbf{X}_{l}\left(N^{\prime}+1\right) & \cdots & \mathbf{X}_{l}(N)\end{array}\right)$,

where $N^{\prime}=N-M+1$. The covariance matrix $\mathbf{T}_{l, l^{\prime}}$ between two time-series $\mathbf{X}_{l}(t)$ and $\mathbf{X}_{l^{\prime}}(t)$ has an $(M \times M)$ size and is given by:

$\left(\mathbf{T}_{l, l^{\prime}}\right)_{j, j^{\prime}}=\frac{1}{\tilde{N}} \sum_{n=\max \left(1,1+j-j^{\prime}\right)}^{\min \left(N, N+j-j^{\prime}\right)} \mathbf{X}_{l}(n) \mathbf{X}_{l^{\prime}}\left(n+j^{\prime}-j\right)$, 
with

$\tilde{N}=\min \left(N, N+j-j^{\prime}\right)-\max \left(1,1+j-j^{\prime}\right)+1$.

These matrices are the blocks of a grand covariance matrix $\widetilde{\mathbf{T}}$ of size $(L \times M) \times(L \times M)$ :

$\widetilde{\mathbf{T}}=\left(\begin{array}{cccccc}\mathbf{T}_{1,1} & \mathbf{T}_{1,2} & \cdot & \cdot & \cdot & \mathbf{T}_{1, L} \\ \mathbf{T}_{2,1} & \mathbf{T}_{2,2} & \cdot & \cdot & \cdot & \mathbf{T}_{2, L} \\ \cdot & \cdot & \cdot & \cdot & \cdot & \cdot \\ \cdot & \cdot & \cdot & & \mathbf{T}_{l, l^{\prime}} & \cdot \\ \cdot & \cdot & \cdot & \cdot & \cdot & \cdot \\ \mathbf{T}_{L, 1} & \mathbf{T}_{L, 2} & \cdot & \cdot & \cdot & \mathbf{T}_{L, L}\end{array}\right)$.

The eigenvalues $\lambda_{k}$ and eigenvectors $\mathbf{E}^{k}$ diagonalize the matrix $\widetilde{\mathbf{T}}$, cf.

$\tilde{\mathbf{T}} \mathbf{E}^{k}=\lambda_{k} \mathbf{E}^{k}$.

The eigenvectors $E^{k}$ are called spatio-temporal EOFs (ST-EOFs) and are concatenations of $L$ segments $\mathbf{E}_{l}^{k}$ of length $M$. The projection of the rows of the matrix $\widetilde{\mathbf{X}}=\left(\widetilde{\mathbf{X}}_{1}, \widetilde{\mathbf{X}}_{2}, \ldots, \widetilde{\mathbf{X}}_{L}\right)$ onto the eigenvectors $\mathbf{E}^{\mathrm{k}}$ gives the corresponding spatio-temporal principal components (ST-PCs) $\mathbf{A}^{k}(t)$ :

$\mathbf{A}^{k}(t)=\sum_{j=1}^{M} \sum_{l=1}^{L} \mathbf{X}_{l}(t+j-1) \mathbf{E}_{l}^{k}(j)$.

The ST-PCs $\left\{\mathbf{A}^{k}(t): k=1, \ldots, L \times M\right\}$ can be thought of as temporal modes of variability that are shared across the time-series being analysed. The eigenvalues $\left\{\lambda_{k}\right\}$ constitute the eigenspectrum; each of them equals the fraction of the variance of the entire data set that is captured by the corresponding ST-PC. We shall also refer to the ST-PCs as simply PCs, for brevity.

Given the eigendecomposition above, one can partially reconstruct the time-series $\mathbf{X}_{l}(t)$ using the ST-PCs and ST-EOFs (Ghil \& Vautard 1991; Vautard et al. 1992). The partially reconstructed signal $\mathbf{R}_{l}^{k}(t)$ associated with the ST-EOF $\mathbf{E}^{k}$ and ST-PC $\mathbf{A}^{k}$ is given by:

$$
\begin{cases}\mathbf{R}_{\mathbf{l}}^{\mathbf{k}}(\mathbf{t})=\frac{1}{\mathbf{M}} \sum_{\mathbf{j}=1}^{\mathbf{M}} \mathbf{A}^{\mathbf{k}}(\mathbf{t}-\mathbf{j}+\mathbf{1}) \mathbf{E}_{\mathbf{l}}^{\mathbf{k}}(\mathbf{j}) & \text { for } \quad M \leq t \leq N-M+1, \\ \mathbf{R}_{l}^{k}(t)=\frac{1}{T} \sum_{j=1}^{t} \mathbf{A}^{k}(t-j+1) \mathbf{E}_{l}^{k}(j) & \text { for } \quad 1 \leq t \leq M-1, \\ \mathbf{R}_{l}^{k}(t)=\frac{1}{N-t+1} \sum_{j=t-N+M}^{M} \mathbf{A}^{k}(t-j+1) \mathbf{E}_{l}^{k}(j) & \text { for } \quad N-M+2 \leq t \leq N .\end{cases}
$$

These partial reconstructions (RC) $\left\{\mathbf{R}_{l}^{k}\right\}$ are filtered versions of the original time-series that contain only the spatio-temporal modes selected. The original time-series can be reconstructed by summing the entire set of $\mathbf{R}_{l}^{k}(t)^{\prime}$ 's:

$\mathbf{X}_{l}(t)=\sum_{k=1}^{L * M} \mathbf{R}_{l}^{k}(t)$

Note that the ST-PCs $\mathbf{A}^{k}(t)$ have length $N^{\prime}$, while the $\operatorname{RCs} \mathbf{R}_{l}^{k}(t)$ have full length $N$.

\subsection{Step 1}

We simultaneously apply M-SSA to the five time-series of each of the $8277 \mathrm{SH}$ coefficients of DDK7-filtered GRACE Level-2 solutions from the five processing centres described in Section 2, over the time interval August 2002-March 2016, that is, $N=164$ months and $L=5$. We use a lag window of size $M=13$ months in order to capture the annual signal that dominates the GRACE time-series. This first step of our filtering procedure is somewhat related to the filtering in the time-domain of each SH proposed by Wouters \& Schrama (2007) except that we involve here the data from five processing centres and use then the M-SSA rather than a simple SSA.

Data gaps exist in the GRACE time-series and need to be filled prior to the M-SSA analysis. To do so, we used a data-adaptive gap-filling algorithm based on single-channel singular spectrum analysis (SSA gap filling: Kondrashov et al. 2005; Kondrashov \& Ghil 2006). First, we linearly interpolate the $n$ missing data $\left\{d_{k}: 1 \leq k \leq n\right\}$, with $n \ll N$, in each SH coefficient time-series $\mathbf{X}_{l}(t)$ independently. Next, we perform an SSA analysis iteratively until the $\chi^{2}$,

$\chi^{2}=\left\{\frac{\sum_{k=1}^{n}\left(d_{k}^{(p-1)}-d_{k}^{(p)}\right)^{2}}{\sigma_{(p-1)} \cdot \sigma_{p}}\right\}^{1 / 2}$,

between the reconstructed missing signal at iteration $p,\left\{d_{k}^{(l, p)}: 1 \leq k \leq n\right\}$, with associated least-square error $\sigma^{(p, l)}$, and its previous iteration $p-1$, satisfies $\chi^{2}<0.1$. In the above equation we dropped the index $l$ of the time-series being interpolated for simplicity. 


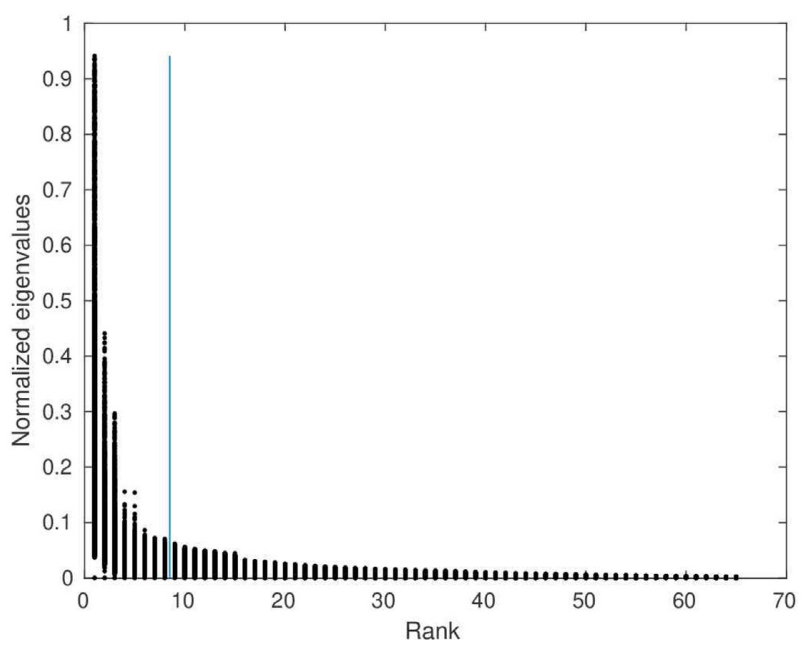

Figure 2. Normalized 65 leading eigenvalues from all 8277 M-SSA analyses performed on the spherical harmonics (SH) coefficients available in the GRACE solutions from the five analysis centres in Table 1 (one spectrum per SH, i.e. one per M-SSA analyses). The blue line is placed after rank 8, the rank after which the eigenvectors are not used in our reconstructions.

Fig. 2 shows the normalized 65 leading eigenvalues obtained from all the M-SSA analyses of the SH coefficient series from the five GRACE analysis centres used in this work. One observes a rapid decrease in the normalized eigenvalues, with a low plateau starting roughly at rank 8 . The first 8 corresponding ST-EOFs capture, therefore, most of the variance of the original data set, while the other ST-EOFs represent what we shall consider as noise in the data. These 8 leading ST-EOFs capture around 83 per cent of the total variance up to degree 20 , around 60 per cent for degrees 21-40, and around 50 per cent for degrees 41-90.

Fig. 3 shows the RCs - arbitrarily combined based on similar temporal variation modes - obtained from the M-SSA spatio-temporal decomposition of the time-series of SH coefficients $C_{3.1}$ from the five processing centres; note that for this coefficient, some of the noise may be due to its resonance with the Earth rotation. Here we use the standard notation $C_{l . m}$ for SHs, with $l$ the degree and $m$ the order. The RCs of other SH coefficients are given in Fig. S3.

In this particular case, the first 8 ST-PCs capture about 80 per cent of the total variance of the data set. Here RCs $1-8$ in panels (a)-(c) of Fig. 3 represent a long-term nonlinear trend (RCs 1+7), annual (RCs $2+3$ ) and semi-annual (RCs 4-6+8) signals and they show a strong correlation among all five GRACE solutions, but RC 9 in panel (d) does not. We discarded, therefore, this component from the analysis. In panel (e), moreover, we notice that the reconstructed signal based on the first 8 ST-PCs is generally consistent among all five analysis centres, but may sometimes differ for one of them, as seen during year 2003 or in late 2011-early 2012.

We similarly computed an M-SSA decomposition for each of the $8277 \mathrm{SH}$ coefficients from the five GRACE processing centres, and reconstructed a filtered signal by retaining RCs 1-8 only, considering that after the eighth component, noise becomes larger than the retrieved geophysical signal. We finally average these five reconstructions, as shown by the black curve in Fig. 3(e). This procedure amounts to a 'smart mean' that exploits the coherent signals from the five independent GRACE processing centres, while filtering out the noise (which of course contributes to the signal variance) — without using a priori information or any hypothesis on the structure of the noise. Note that when a centre doesn't provide a SH coefficient, due to the difference in maximum degree, we apply our M-SSA analysis to all the available time-series for this SH coefficient.

The resulting, filtered and averaged SH coefficients are then transformed to $1^{\circ} \mathrm{x} 1^{\circ}$ gridded maps of EWH. Fig. 4(a) shows, as an example, a map of the EWH for the month of January 2006, relative to July 2005. As can be seen in Fig. S4(b), adding more PC essentially adds stripes (i.e. noise). The comparison with the widely used mean of the CSR, GFZ and JPL EWH solutions, after application of the DDK5 filter (Fig. 1a), shows that the intermediate M-SSA GRACE solution, obtained after this first step, in panel (a) here reduces considerably the north-south stripes, while preserving the location and shape of geophysical signals. The amplitude ratio of the spherical harmonics coefficients before and after filtering with the DDK7 filter and before and after applying the M-SSA on the SH are presented in Fig. S5. It can be seen that the M-SSA reduces significantly the amplitude of large degree and particularly large order spherical harmonics (by a factor close to 2). However, the effect of M-SSA is very different from that of a classical (Gaussian, DDK) spatial filter. M-SSA removes the erratic part of the time-dependent signal but not the coherent part.

\subsection{Step 2}

To further improve the intermediate M-SSA GRACE solution described in the previous section, while keeping 8 modes of the M-SSA filtered spherical harmonics coefficients, and to reduce the residual spatial noise, we now apply the M-SSA method to the time-series of EWH gridded maps based on the M-SSA-derived SHs, such as the one in Fig. 4(a). To do so, we apply M-SSA to the EWH time-series at each point of the $1^{\circ} \times 1^{\circ}$ grid, simultaneously with EWH time-series at six neighbouring points that are located at the same latitude and spaced $2^{\circ}$ apart, see 


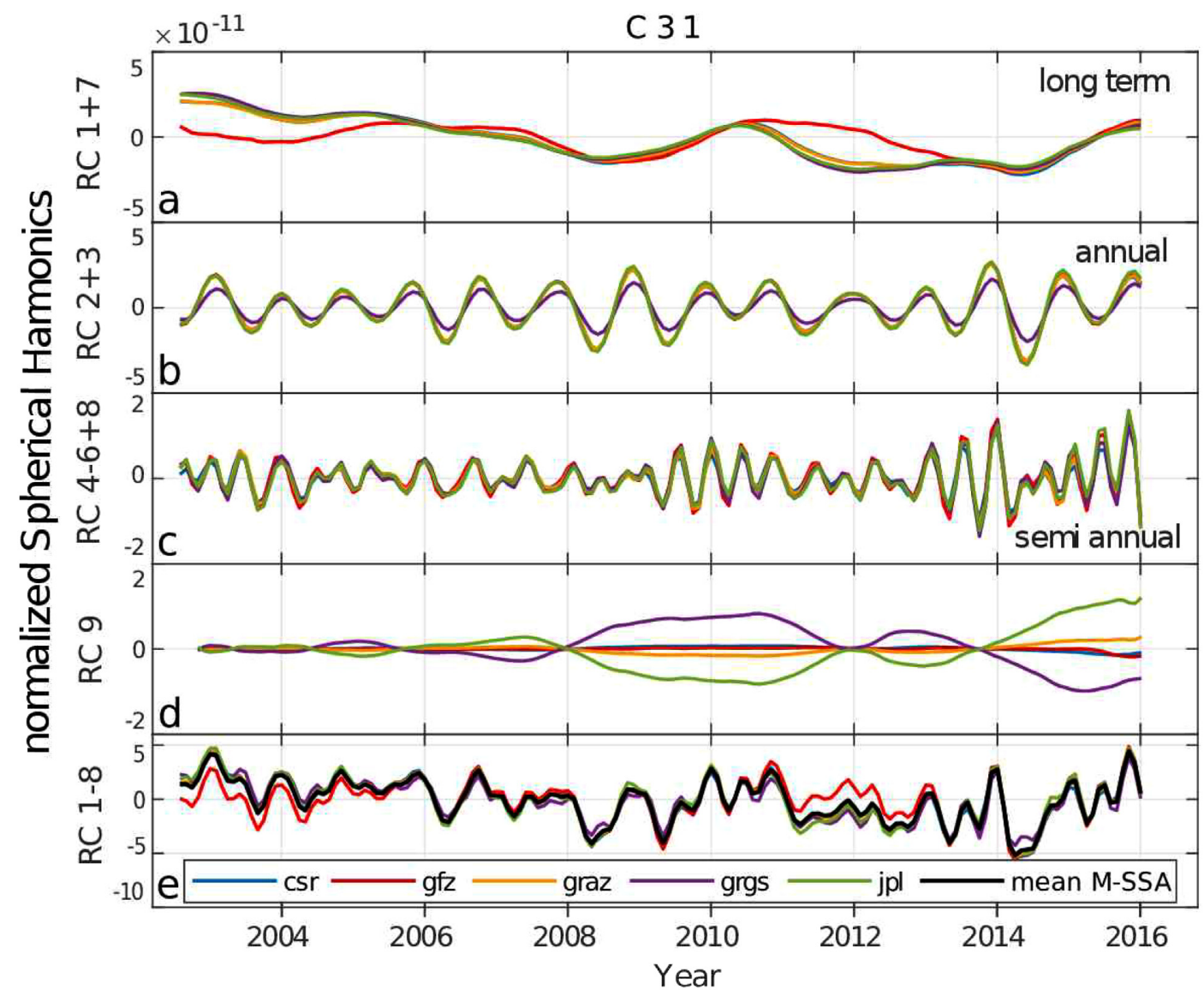

Figure 3. Multichannel singular spectrum analysis (M-SSA) decomposition of GRACE SH $C_{3.1}$. The source of the Level-2 data is shown by colours: CSR (blue), GFZ (red), GRAZ (yellow), CNES/GRGS (purple) and JPL (green). The first 3 panels, (a)-(c), show a visually made combinations of partial reconstructions (RCs) of similar nature for each processing centre. These RC combinations correspond to (a) long-term trend, along with (b) annual and (c) semi-annual signals that are all three coherent between processing centres, while the 9th RC in panel (d) shows discrepancies between centres; the latter are most likely due to differences in processing strategies. The bottom panel (e) shows the signal reconstructions using the first 8 RCs for each of the five GRACE solutions, as well as their mean (black).

Fig. 5(f). The choice of the localization and of the number of points is linked to the shape and width of the north-south stripes, and it takes into account the rapid increase in computing time as the number of time-series considered increases.

The final GRACE M-SSA solution is given by the RCs of the EWH decomposition, where we retain the eight leading components that allow us to reconstruct the dominant part of the signal, while reducing the noise. Fig. 5 shows the M-SSA decomposition of the EWH time-series at latitude $41^{\circ} \mathrm{N}$ and longitude $51^{\circ} \mathrm{E}$, in the Caspian Sea. Similar times-series are given at other grid points (in Albania and Brasil) in Fig. S6. For the point in Fig. 5, by applying M-SSA to the EWH time-series, we retrieve (a) a long-term variation, (b) a strong annual mode, (c) a long-term oscillating mode and (d) a semi-annual mode. All four components are statistically robust, that is statistically significant and encompass a window length from a few months to a decade. Therefore, they are likely to be geophysical signals.

Fig. 4(b) shows the final M-SSA solution of GRACE mass anomaly for the month of January 2006 relative to July 2005 and Fig. 6 shows the mean rate of mass variations form January 2003 to December 2014. North-south stripes have been efficiently reduced and coherent signals are preserved in terms of location and shape in regions in which a geophysical signal is expected - whether due, for instance, to post-seismic deformation or to surface loading. For example, in terms of continental hydrology, the signal in the M-SSA solution of Fig. 4(b) is more compact in the Amazon basin and in West and South Africa than in the standard SH solution of Fig. 1(a). The amplitude ratio of the signal before and after step 2 is provided in Fig. S5. Here again, we emphasize the fact that M-SSA only reduces the temporally incoherent part of the signal as will be shown in the next section.

\subsection{Synthetic tests}

In order to evaluate the methodology used here to retrieve the physical signal from GRACE, we ran two kinds of tests: 

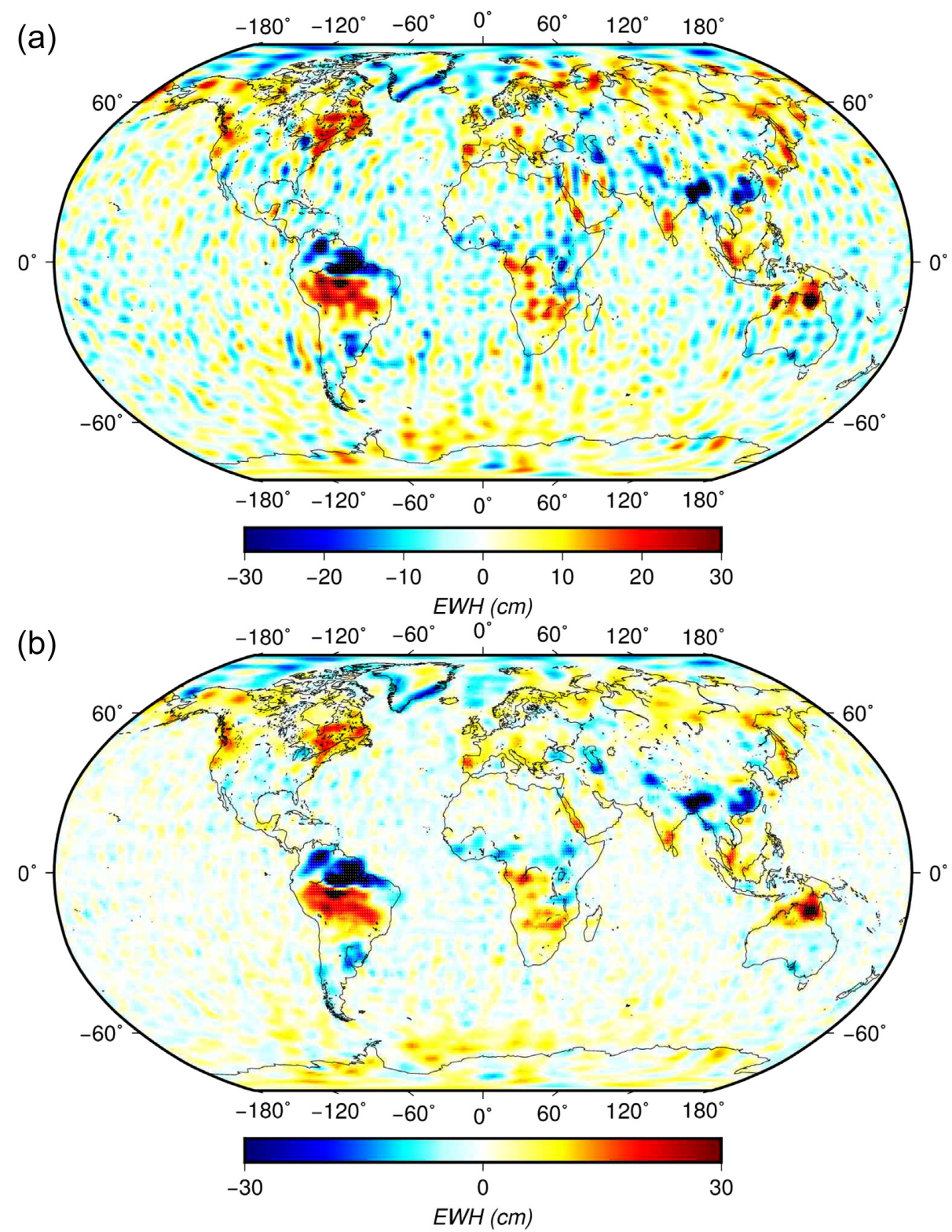

Figure 4. Surface mass density anomalies solutions for January 2006 relative to July 2005, expressed in equivalent water height (EWH, in $\mathrm{cm}$ ). (a) the intermediate M-SSA GRACE solution after step 1 obtained from the mean of all five processing centres' signals filtered with DDK7 and reconstructed from the leading 8 RCs of the M-SSA applied to SHs and (b) the final M-SSA GRACE solution.

\subsubsection{A test on north-south stripes}

With this first test, we seek to determine how the M-SSA method erases or preserves north-south stripes depending upon their temporal modulation. Because spurious NS stripes in GRACE data are caused by dealiasing errors in model predictions and accelerometer noise, they are expected to appear at random times in a given area. On the opposite, an actual geophysical signal that would also have a spatial pattern elongated in a NS direction would have common temporal variation modes with the surrounding areas at the GRACE data spatial scale. Because of the very different temporal characteristics of noise and signal, the M-SSA should be able to remove a NS stripe that appears at random times but preserve a NS stripe that corresponds to an actual geophysical signal.

We tested this by adding a NS stripe in South America to our final solutions, which consist of one realization per month from 2002 to 2016, with two temporal patterns represented schematically at the top of Fig. 7. In the first case, the NS stripe is introduced into one of the months only (Fig. 7b). This is meant to simulate a spurious NS stripe that one seeks to filter out. In a second case, the NS stripe is modulated in amplitude through time with an annual period across the 162 realizations. This is meant to simulate a geophysical signal of interest elongated in the NS direction. The maximum amplitude of the stripe is $10 \mathrm{~cm}$ EWH in both cases, as shown in Fig. 7(a).

As shown on Fig. 7, the M-SSA method effectively removes the spurious NS stripe (Fig. 7b) but preserves the simulated annual geophysical signal (Fig. 7c). This is due to the fact that the annual mode of variability introduced is one of the leading ones in the actual 

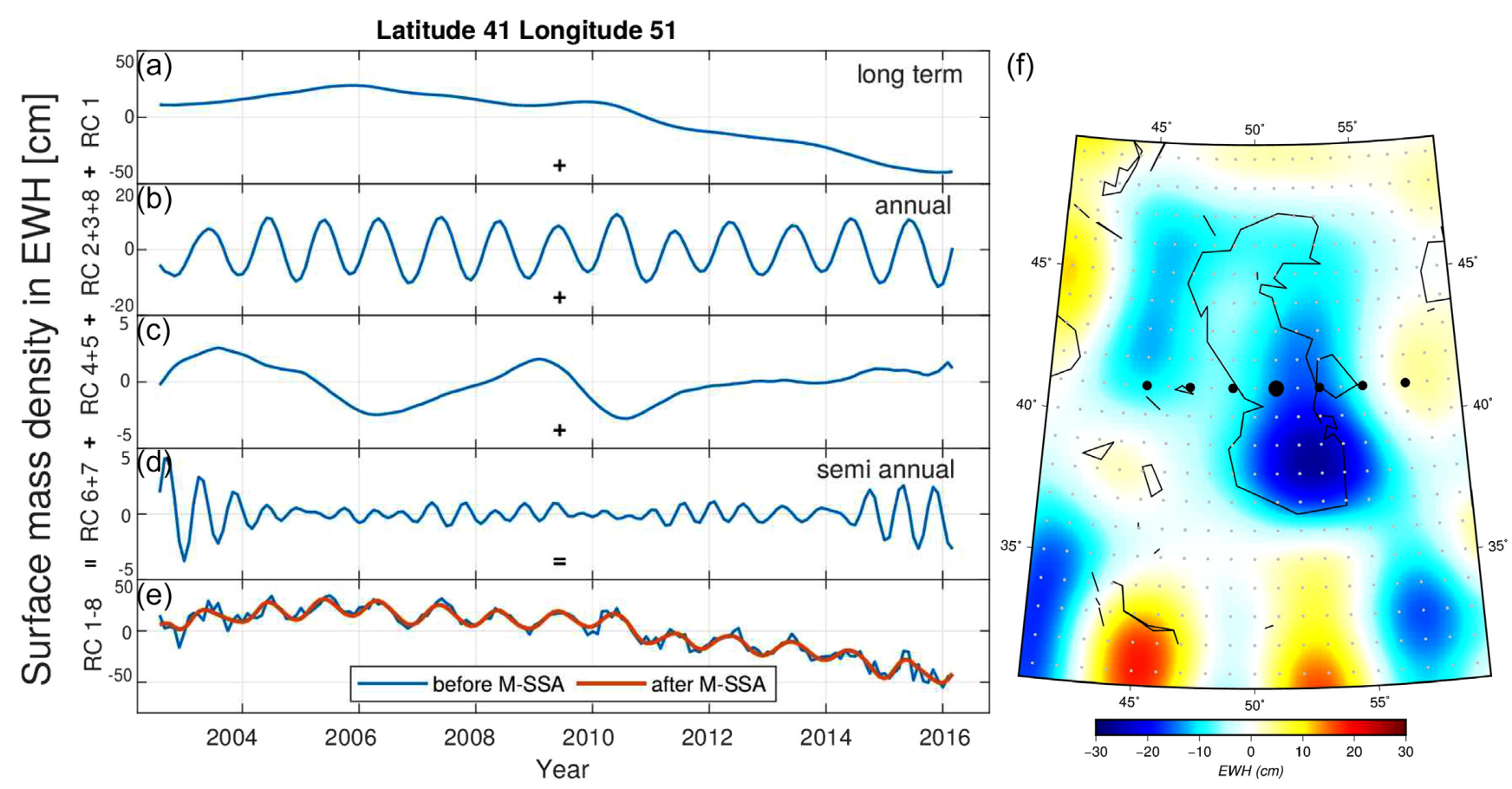

Figure 5. (a)-(e): M-SSA-based spatio-temporal decomposition of GRACE data-derived surface mass density anomalies time-series at latitude $41^{\circ} \mathrm{N}$ and longitude $51^{\circ} \mathrm{E}$, in the Caspian Sea. The first 4 panels show a single RC, in panel (a), or a sum thereof, in panels (b)-(d). Panel (e) shows the time-series prior to the final M-SSA (blue) and the signal reconstructed using the leading $8 \mathrm{RCs}$ of the gridded EWH values (red). (f) Surface mass density anomalies around the Caspian Sea for January 2006 relative to July 2005, expressed in s(EWH, in cm) from the intermediate M-SSA GRACE solution after step 1 obtained from the mean of all 5 processing centres' signals reconstructed from the leading 8 RCs of the M-SSA applied to SHs. In black, the points of the seven time-series used in the M-SSA spatio-temporal decomposition presented in panels (a-e) for computing the time-serie for the central point.

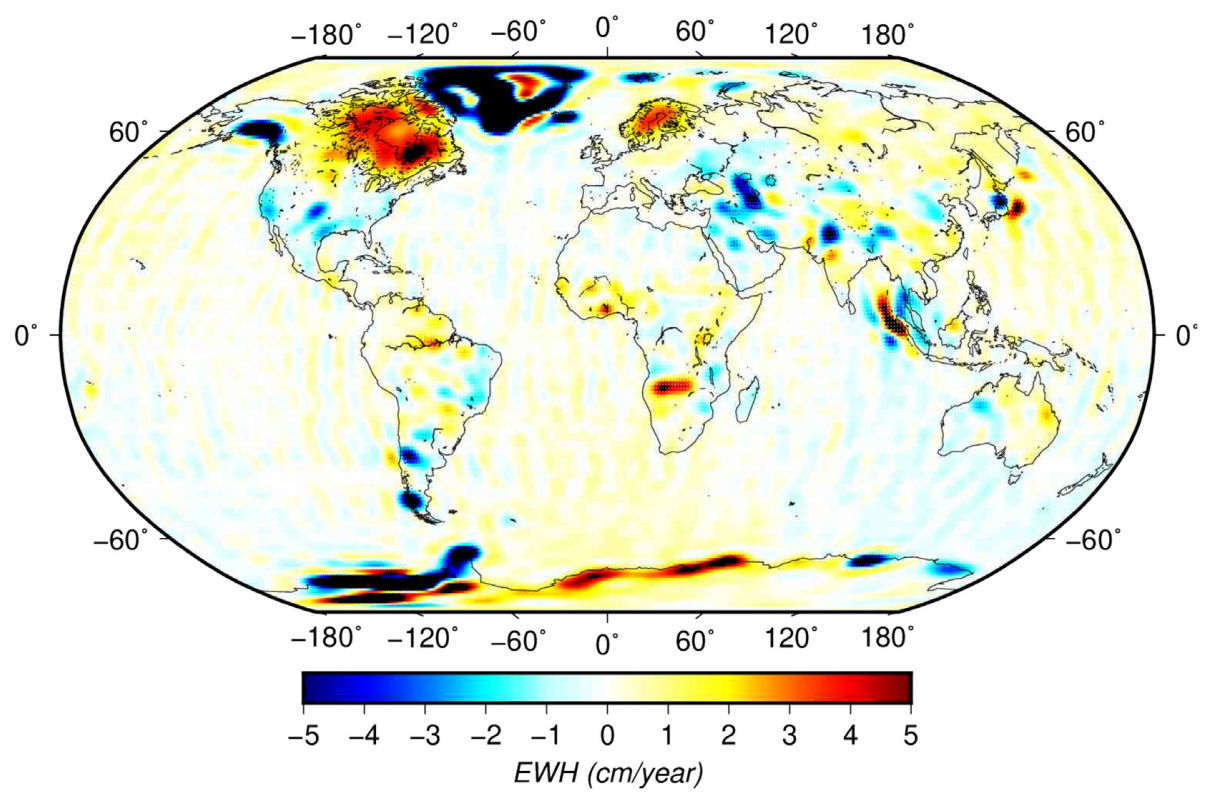

Figure 6. Mean rate of surface mass density variations from January 2003 to December 2014 expressed in equivalent water height (EWH) per year, given in $\mathrm{cm}(\mathrm{yr})^{-1}$, for the final M-SSA GRACE solution.

geophysical signal that surrounds the NS stripe. It is therefore preserved by the M-SSA, while the one-time stripe, which is not correlated in time with its surroundings, is removed.

This simple test shows that the M-SSA can efficiently eliminate spurious stripes while preserving geophysical signals whose temporal patterns are present in the surroundings. However, if erratic local peaks were present in the hydrological signal, they would also be suppressed by the M-SSA procedure. 
(a)

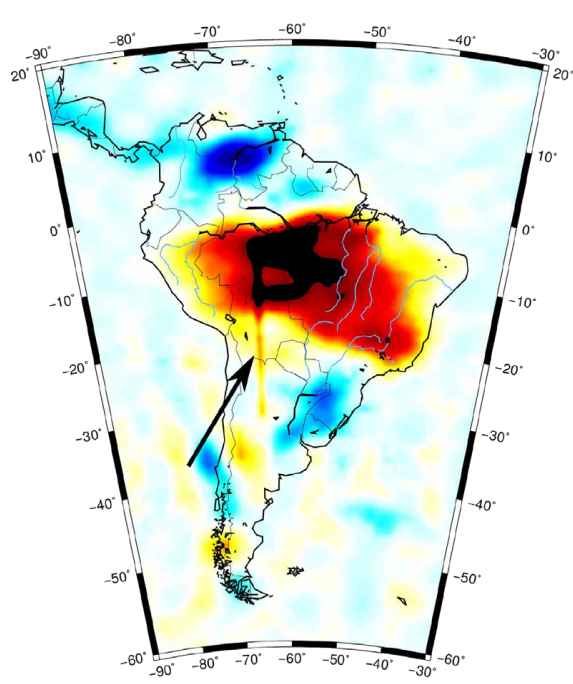

(b)

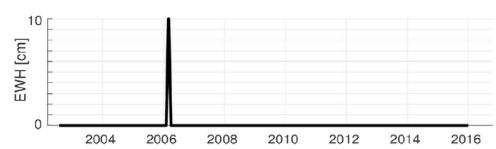

(c)

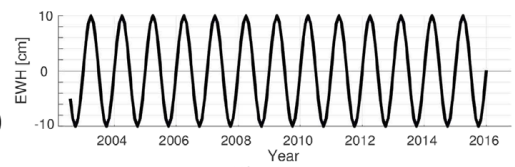

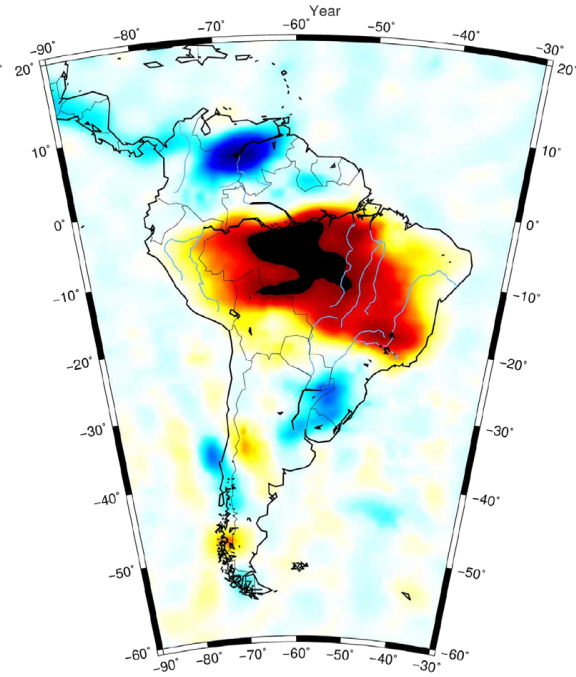

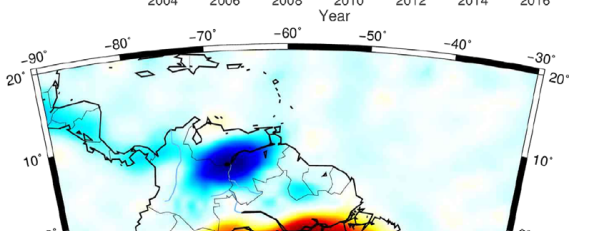

Figure 7. Surface mass density anomalies solutions for March 2006, expressed in equivalent water height (EWH, in cm). (a) The M-SSA GRACE solution in South America with a north-south stripe of $10 \mathrm{~cm}$ amplitude (shown by the black arrow); (b) the solution obtained using the M-SSA on a signal with one-time stripe inserted in March 2006; and (c) the solution obtained using the M-SSA on a signal with a stripe modulated in amplitude through time with an annual period. The time modulation of the stripe is indicated on top of the figure.

\subsubsection{A test on the GLDAS model data}

With this second test, we seek to determine whether the M-SSA method preserves the actual spatial and temporal modulations of the global hydrological signal. To do so, we use version 2.1 of the Global Land Data Assimilation System (GLDAS), which is based on land surface modelling and data assimilation (Rodell et al. 2004; Beaudoing \& Rodell 2016). We expect such a model to contain the same space- and time-dependent features as the actual hydrological signal we seek to retrieve from GRACE, without being affected by erratic NS stripes of course.

We build the input signal by adding the monthly $1^{\circ} \times 1^{\circ}$ GLDAS grids for terrestrial water storage corresponding to snow, canopy and soil water between the surface and $2 \mathrm{~m}$ depth (Fig. 8a, GLDAS model data from https://giovanni.gsfc.nasa.gov/giovanni/\#service=TmAvM p\&starttime= \&endtime $=\&$ dataKeyword=GLDAS_NOAH10_M). We then apply to the resulting grids (1) the DDK7 filter only and (2) the second step of the M-SSA method from August 2002 to March 2016. As described above the M-SSA method uses the DDK7-filtered signal as starting point. Fig. 8 shows the result in terms of the EWH difference between the months of January 2006 and July 2005.

The DDK7-filtered solution, displayed in Fig. 8(b), simply smoothes the input signal. A small amplitude spurious signal elongated mainly in the north-south direction is visible in the oceans: this is an expected consequence of the filtering of a high amplitude spot on a continent by a decorrelating filter (see fig. 4 of Swenson \& Wahr 2006). The general shape and amplitude of the original signal are otherwise well preserved.

The M-SSA solution, displayed in Fig. 8(c), is very similar to the DDK7-filtered one of Fig. 8(b). Indeed, the 8 leading ST-PCs of the M-SSA used here retrieve more than 98 per cent of the input signal. Therefore, in the likely hypothesis that the actual hydrological signal has the same spatial and temporal characteristics as the GLDAS model data, it is appropriate to apply the M-SSA procedure to retrieve hydrological signals from GRACE data.

The amplitude ratio of the spherical harmonics coefficients from GLDAS data before and after filtering with the DDK7 filter and before and after applying the M-SSA on the grid are presented in Fig. S7. It can be seen that while the DDK7 filter reduces significantly the amplitude of the small wavelength (large degree) signal, the MSSA itself keeps most of the remaining signal (more than 96 per cent).

We also compare in Fig. S8 the EWH time-series at six locations where the hydrological signal is important, one in North America, one in South America, two in Europe, one in Asia, and one in Africa. We observe that the eight leading components used for the M-SSA reconstructions allow for an accurate reproduction of the input GLDAS signal, except for a few sharp peaks that mostly appear at the Colorado location (Fig. S8a). There, the M-SSA reconstruction reproduces well the 2012 drought but misses spikes present in the GLDAS input signal in 2009 and 2015, for instance. This may result from the fact that the M-SSA method, by construction, removes information that is not correlated in time and space. When we add a few more RCs, the sharp peaks are still poorly reproduced as shown in Fig. S8(a). 

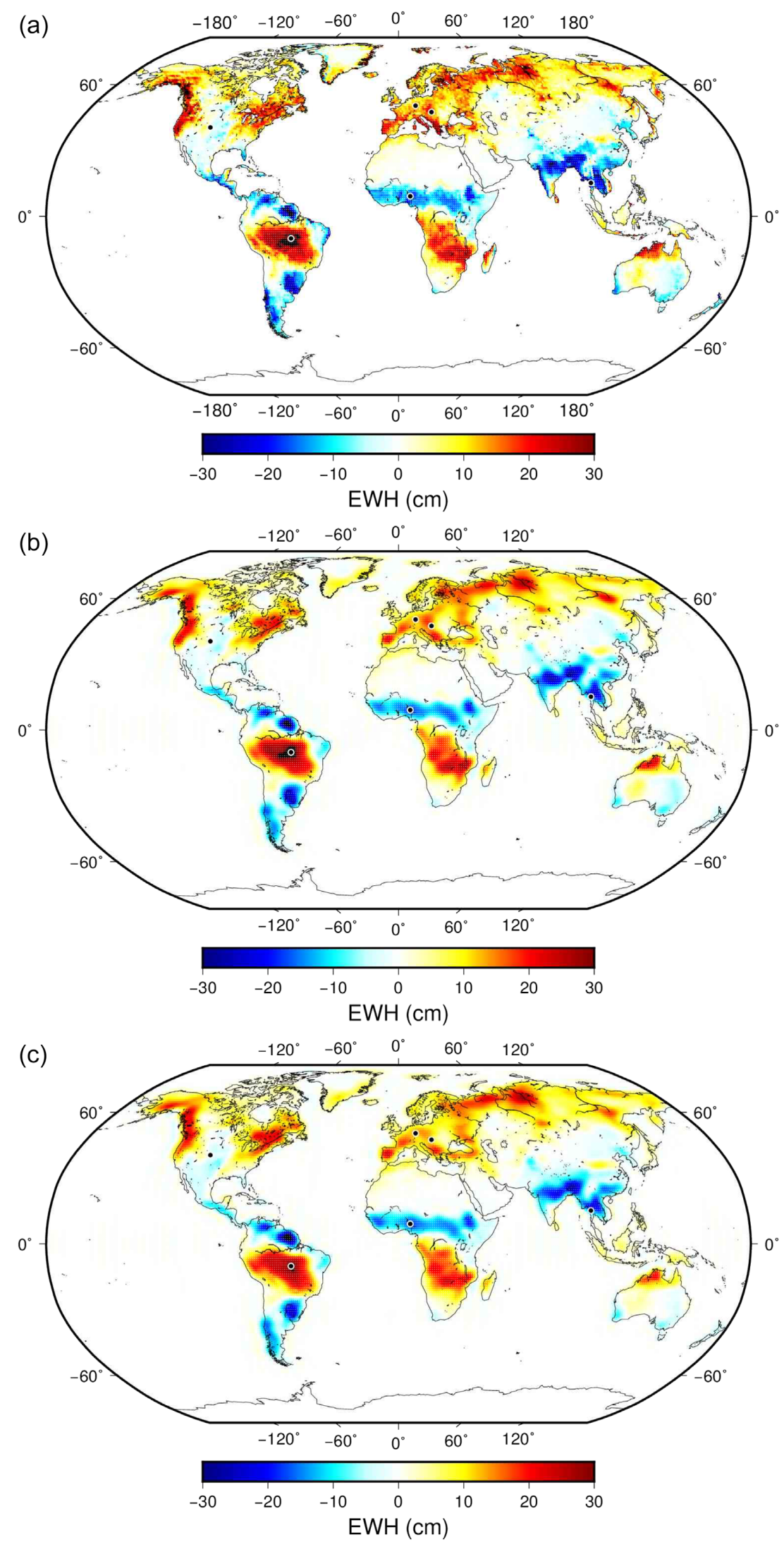

Figure 8. Total water storage from GLDAS data for January 2006 relative to July 2005, expressed in equivalent water height (EWH, in cm): (a) before any filter; (b) after the DDK7 filter (c) after M-SSA on the data filtered with DDK7. The black dots are the points for which we plotted the time-series before and after M-SSA in Fig. S8. 
The other locations displayed on Fig. S8 show a very good agreement between the input GLDAS model data and the M-SSA reconstructions. This is expected for the quasi-sinusoidal time-series at a location in Brazil (Fig. S8b) but also visible for more irregular ones. For instance, the summer droughts of 2003 and 2015 in Europe are well-reproduced at a location in Germany (Fig. S8c). Also, the Danube basin wet summers of 2005, 2010 and 2014, associated with elevated soil water content, are visible at a location near Budapest (Fig. S8d). We also chose a coastal location in Thailand (Fig. S8f) in order to detect potential artefacts (i.e. leakage due to the interface between continental area with hydrological signal and oceanic area without signal), but find that the input time-serie at that location is also well reproduced by the M-SSA method.

\section{DISCUSSION}

\subsection{Global comparison}

\subsubsection{Comparison with other SH solutions}

Here, we compare, the M-SSA GRACE solution with two other SH solutions. The first one is the average of the solutions from the three official GRACE processing centres (CSR, GFZ and JPL), where the DDK5 filter is applied (Sakumura et al. 2014). This solution, recommended by the official centres and largely used, is plotted in Fig. 1(a). The second one is the mean of the five solutions used in this study, filtered with the weaker DDK7 filter, which is the starting filter applied before implementing the M-SSA analysis described above.

Fig. S9 shows the differences between the mean of all five GRACE solutions, each filtered by DDK7 and the M-SSA solution in the left panel, and between the mean of the DDK5-filtered solutions of the three official centres (CSR, JPL and GFZ) and the M-SSA solution in the right-hand panel; once more, the plots are for the month of January 2006, relative to July 2005. Similar maps but for mass rate differences between January 2003 and December 2014 are given in Fig. S10 and similar maps for difference with the five GRACE SH solutions are given in Fig. S11.

These maps show that the M-SSA methodology, as used in this study, is efficient at removing north-south stripe artefacts from GRACE SH solutions, whether compared to solutions filtered with DDK5 or DDK7. The M-SSA method allows one to start with the DDK7-filtered solutions therefore producing a less smoothed geophysical signal than the one present after DDK5 filtering (Figs 1a and 4b).

The final M-SSA GRACE solution, as illustrated in Fig. 4(b), contains limited spurious noise and more localized signals than the recommended 3-centre average of GRACE SH solutions in Fig. 1(a). Excellent localization is apparent, for example, in the Amazon basin, in West and South Africa and around the Caspian Sea.

\subsubsection{Comparison with mascon solutions}

Mascons are mass concentration blocks, onto which GRACE ranging observations are fitted by an inversion procedure (Luthcke et al. 2013; Watkins et al. 2015; Save et al. 2016). Mascon solutions allow for geophysical constraints to be implemented within the GRACE data processing, contrary to the standard SH approach. A priori geophysical constraints help reduce GRACE Level-2 noise compared to the standard post-processing by DDK filtering. Due to the use of these constraints, mascon solutions do not allow north-south stripes and exhibit well-localized hydrological signals with no significant leakage effect, as seen, for instance, in Fig. 9(a) for the Amazon basin or the Greenland ice mass loss.

In this comparison, we use a CSR solution plotted on a $0.5^{\circ} \times 0.5^{\circ} \mathrm{EWH}$ grid (Save et al. 2016), in which the a priori information was derived from GRACE itself, using SH solutions. For instance, the inverse method used to build this mascon solution uses a regularization procedure which tends to confine the solution over most of the oceans close to the zero imposed with respect to the a priori model.

Fig. 9 shows maps of the amplitude of mass anomalies for January 2006 relative to July 2005, first for the CSR mascon solution of Save et al. (2016) and then for the difference between the CSR solution and the M-SSA GRACE solution with the ocean de-aliasing model restored. The de-aliasing models from the different centres presented in Table 1 are averaged and added to the final M-SSA GRACE solution; this corrected solution is illustrated in Fig. S12. Similar maps of mass anomalies are given for the JPL and Goddard mascon solutions in Fig. S13 and the corresponding mass rates in Figs S14 and S15. Note that the huge differences around Greenland and West Antarctica are due to the leakage over the ocean of the large mass variations associated with ice melting in the spherical harmonics solutions while, in the mascons solutions, the inversion favors mass variations over the continents.

As expected, the difference between the CSR mascon and M-SSA solutions shows residual north-south stripes in the latter. In addition, this difference also appears to include some geophysical signals, which we address in the following subsection by studying in greater detail the regional maps for the Caspian and Aral Seas, along with those for recent mega-earthquakes. We also note that the differences between the CSR mascon and M-SSA solutions are of the same order of magnitude as the differences between mascon solutions from different analysis centres, as shown in Fig. S16. 

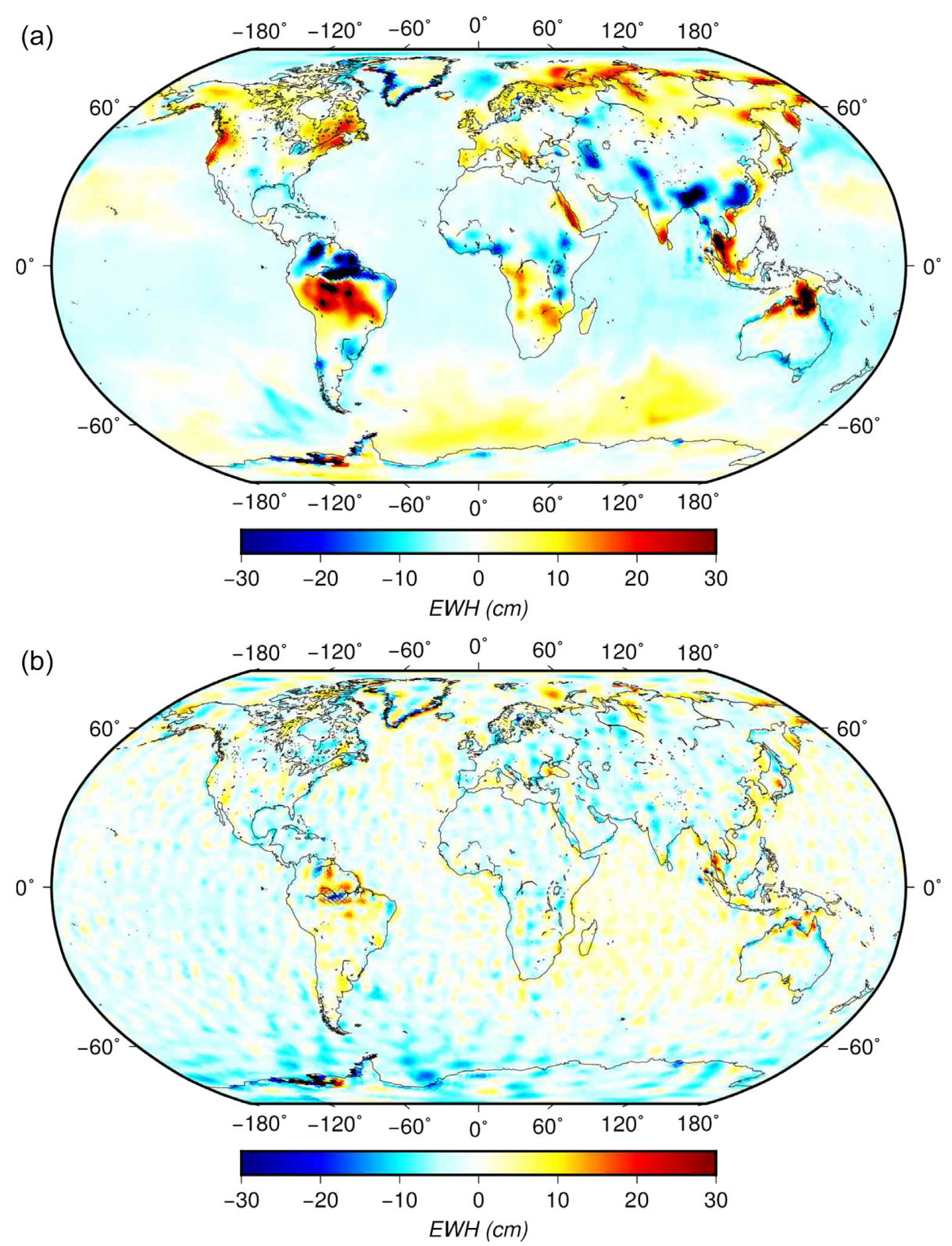

Figure 9. Surface mass density anomalies expressed in cm of equivalent water height (EWH) for January 2006 relative to July 2005: (a) CSR mascon solution and (b) difference between CSR mascons and GRACE M-SSA mass anomalies.

\subsection{Regional comparisons}

\subsubsection{Hydrological signals in the Caspian and Aral Seas regions}

The massive water losses from the Caspian and Aral Seas are a major issue in terms of the region's natural resources, and they have been studied using independent ground-based and satellite data (Swenson \& Wahr 2007; Chen et al. 2017). The Caspian Sea is losing water fast and it can thus provide information about regional and global climate change, as well as about the coastal response pattern to water loss (Chen et al. 2017; Kaplin \& Selivanov 1995).

The spectacular shrinking of the Aral Sea since the 1960s is also an active research topic, as the original decline is due to the diversion of water from the major rivers that feed it into the surrounding cotton fields. This process has induced significant changes of regional climate, leading to great losses of fishery resources and wildlife, along with the development of salt and dust plumes that affect the life of millions of people. There is, therefore, a need to accurately quantify the current water balance of the Aral Basin to evaluate the success of the restoration projects (cf. Crétaux et al. 2005; Micklin 2007; Gaybullaev et al. 2012; Shi \& Wang 2015; Opp et al. 2017).

On the other hand, in Turkmenistan, some $22 \mathrm{~km}^{3} \mathrm{yr}^{-1}$ of water are diverted from the Amu-Daria river to irrigate the fields. In particular, the 1300-km-long Karakum Canal (Zonn 2012) transports water over a long distance, with a termination some $50 \mathrm{~km}$ away from the Caspian sea. In the irrigated parts of Turkmenistan, the soils get saturated with the water diverted from the Amu-Daria and become improper for 
agriculture in many areas (Esenov 2013). To overcome this problem, drainage canals carrying away the salted residual water first to the SaryKamish lake then, since 2009, to the AltynAsyr lake have been dug. Between 2003 and 2007, $10 \mathrm{~km}^{3}$ of water diverted from the Amu Daria river have contributed to the growth of the SaryKamish lake (http://hydroweb.theia-land.fr) but these $10 \mathrm{~km}^{3}$ represent only a small fraction of the volume of water arriving to the lake as most of the water either evaporates or infiltrates in the soil (Pyagay 2012). Concerning the AltynAsyr lake, according to the initial forecasts, $10 \mathrm{~km}^{3} \mathrm{yr}^{-1}$ of water are expected to arrive each year in the lake. However, 35 per cent should evaporate, 45 per cent infiltrate at least during the first decades and 20 per cent contribute to the lake growth (Pyagay 2012). Moreover, most of the canals are unlined and the amount of seepage is not well constrained. Also many little lakes form along the newly dug collector canals. The budget of the $22 \mathrm{~km}^{3} \mathrm{yr}^{-1}$ of water diverted from the Amu Daria river is difficult to establish.

The use of gravimetric data can provide highly useful complementary information for the study of the global water transfers in the Caspian-Aral-Turkmenistan area. In this subsection, we will simply examine the differences between the various GRACE solutions in this area.

Fig. 10 shows the EWH mass rates from January 2003 to December 2014 in and around the Caspian Sea for the standard SH GRACE solution, the M-SSA GRACE solution, and the CSR mascon one. Similar maps are given for the JPL and Goddard mascon solutions in Fig. S17. The standard SH solution shows a significant mass loss in the Caspian Sea, highlighted by rectangle A in Fig. 10(a); this mass loss is slightly more concentrated within the actual area of the sea itself in the mascon solution ( $c f$. Fig. 10c). However, while a mass loss is also observed in the Aral Sea (rectangle B in Fig. 10a) in the standard SH solution, it almost disappears in the CSR mascon solution of panel (c).

The GRACE M-SSA solution in Fig. 10(b), though, does capture this signal, with contours in both the Caspian and Aral Seas that are more sharply focused than in the other solutions. The localized signal is consistent with other studies based, for example, on Moderate-Resolution Imaging Spectroradiometer (Moradi et al. 2014) or on Advanced Very High Resolution Radiometer and Topex/Poseidon-Jason-1-Jason-2 data (Shi et al. 2014) that show a decrease of the volume - and slightly of the surface area - of the Caspian between 2002 and 2013 and a diminution of almost 50 per cent in the surface area of the South Aral Sea during the same time interval.

In addition, a positive mass rate is observed in northern Turkmenistan, south of the Aral Sea, in the standard SH solution, as well as in the M-SSA one, but not in the CSR mascon solutions (rectangle C in Fig. 10a). This mass increase is consistent with independent studies (e.g. Saiko \& Zonn 2000), showing that the construction of irrigation dams on the Amu Darya river, which feeds the Aral Sea, is responsible for a significant increase in water storage within this highly cultivated area. This example of the Caspian Sea shows that the GRACE M-SSA solution is able to preserve the shape of a regional hydrological signal as well as - and perhaps better than - other commonly used GRACE solutions. Concerning the Caspian sea, all models are in close agreement once one considers the water budget over the broad rectangle surrounding the Caspian sea (Fig. 10) and the trends differ by less than 2 per cent (see Table 2), that is by less than $0.7 \mathrm{~km}^{3} \mathrm{yr}^{-1}$. In their thorough study of the water budget of the Caspian sea, Chen et al. (2017) have shown that once leakage from continental water and steric effects were appropriately accounted for, both spherical harmonic and mascon solutions could be reconciled with altimetric data. In this case, the differences between models might be below the uncertainty in the aliasing correction associated with the poorly known water transfer in the Altyn-Asyr lake situated some $150 \mathrm{~km}$ away from the Caspian sea but amounting to several (up to 10 ?) $\mathrm{km}^{3} \mathrm{yr}^{-1}$. Uncertainties on the steric effect may also affect the comparison with altimetry for shorter timescales. For the Aral Sea and Turkmenistan, the hydrological variations occur over a more restricted area. Our study shows that the magnitude of the signal depends strongly upon the GRACE solution used. The use of GRACE data to improve the budget of the water diverted from the Amu Daria, is still very dependent upon the GRACE model used and this example clearly illustrates the need for improvement of GRACE resolution in order to capture water variations at a $500 \mathrm{~km}$ scale.

\subsubsection{Continental mass balance}

In order to further quantify the variability of continental water mass balance estimates from various GRACE solutions, we focused on four areas that exhibit a large hydrological or glacial signal and for which the M-SSA solution presents differences in trend. The time-series for these four areas from several GRACE analysis centres are presented in Fig. S18. The seasonal variations are similar for all the analysis centres but we can see a difference in trend between the solutions based on SHs and the ones based on mascons.

We calculated the percentage of difference $\% \Delta$ in the trends $t r_{\text {sol }}$, from January 2003 to December 2014, between four published solutions and the M-SSA one, for these 4 areas and the 3 from subsection 4.2.1 using:

$\% \Delta=\frac{t r_{\mathrm{sol}}-t r_{\mathrm{MSSA}}}{t r_{\mathrm{MSSA}}} * 100$

These percentages are presented in Table 2. In most of the cases, EWH absolute value of the trends in the M-SSA solution are larger than those from the mascon ones, with the largest difference observed for the CSR-mascon solution. We also note that these differences are larger in areas where a large part of the signal is due to human activity, such as northern India or northern Turkmenistan, where the loss of mass is due to agriculture (Saiko \& Zonn 2000; Rodell et al. 2009) and therefore not shown in most hydrological models. As the true values of these trends are not available, it is difficult to conclude on which solution is the best. However, there are large discrepancies between M-SSA and mascon solutions which can be due to the regularization used for the mascons solutions. 

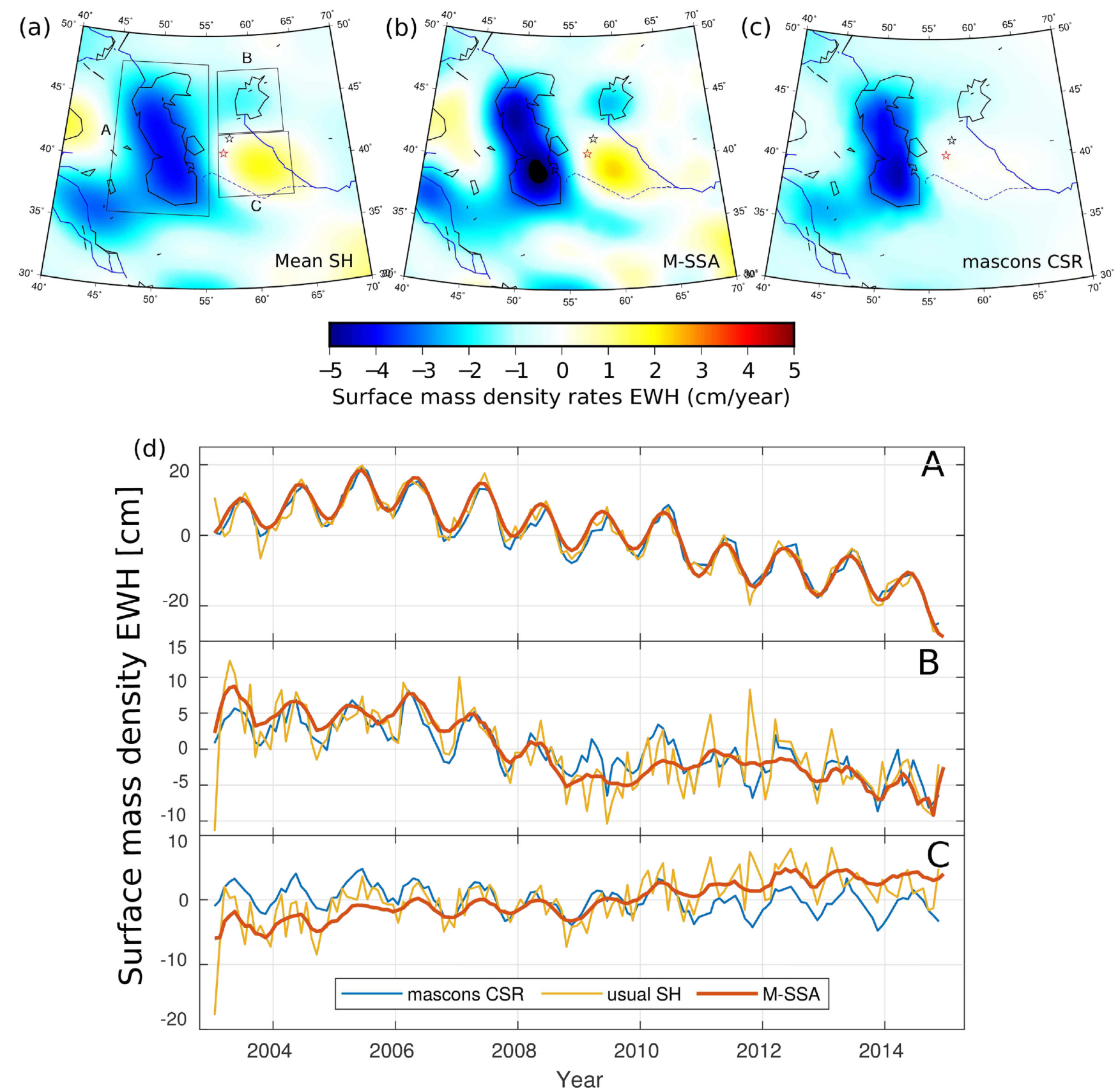

Figure 10. (a)-(c): Surface mass density rates from January 2003 to December 2014 expressed in equivalent water height $(\mathrm{EWH})$ per year (cm yr $\left.{ }^{-1}\right)$ for the Caspian Sea and surrounding regions (where the dashed blue line is the Karakum Canal, the black star is the SaryKamish Lake and the red one the AltynAsyr Lake): (a) The standard SH solution, i.e., the mean of the DDK5-filtered JPL, GFZ and CSR solutions; (b) the M-SSA final solution; and (c) the CSR mascon solution. (d) Time-series of the mass anomalies averaged over each of the three areas for each solution. (A) Caspian Sea, (B) Aral Sea and (C) North Turkmenistan; colors are shown in the panel's legend.

Table 2. Percentage of difference $\% \Delta$ between the equivalent water height trend, from January 2003 to December 2014, based on the M-SSA solution and on four published ones for 7 inland areas; see Fig. 10 and Fig. S18.

\begin{tabular}{|c|c|c|c|c|c|c|c|}
\hline Solution & $\begin{array}{l}\text { Aral Sea } \\
\text { (per cent) }\end{array}$ & $\begin{array}{c}\text { California } \\
\text { (per cent) }\end{array}$ & $\begin{array}{c}\text { Caspian Sea } \\
\text { (per cent) }\end{array}$ & Chile (per cent) & India (per cent) & $\begin{array}{l}\text { Tian Shan } \\
\text { (per cent) }\end{array}$ & $\begin{array}{c}\text { North } \\
\text { Turkmenistan } \\
\text { (per cent) }\end{array}$ \\
\hline Mean SH & -14 & 12 & -1 & 5 & 9 & 4 & -32 \\
\hline Mascons JPL & -7 & 6 & 6 & 2 & 11 & 21 & -95 \\
\hline Mascons GSFC & -40 & -12 & 4 & 4 & -12 & 0.2 & -43 \\
\hline
\end{tabular}




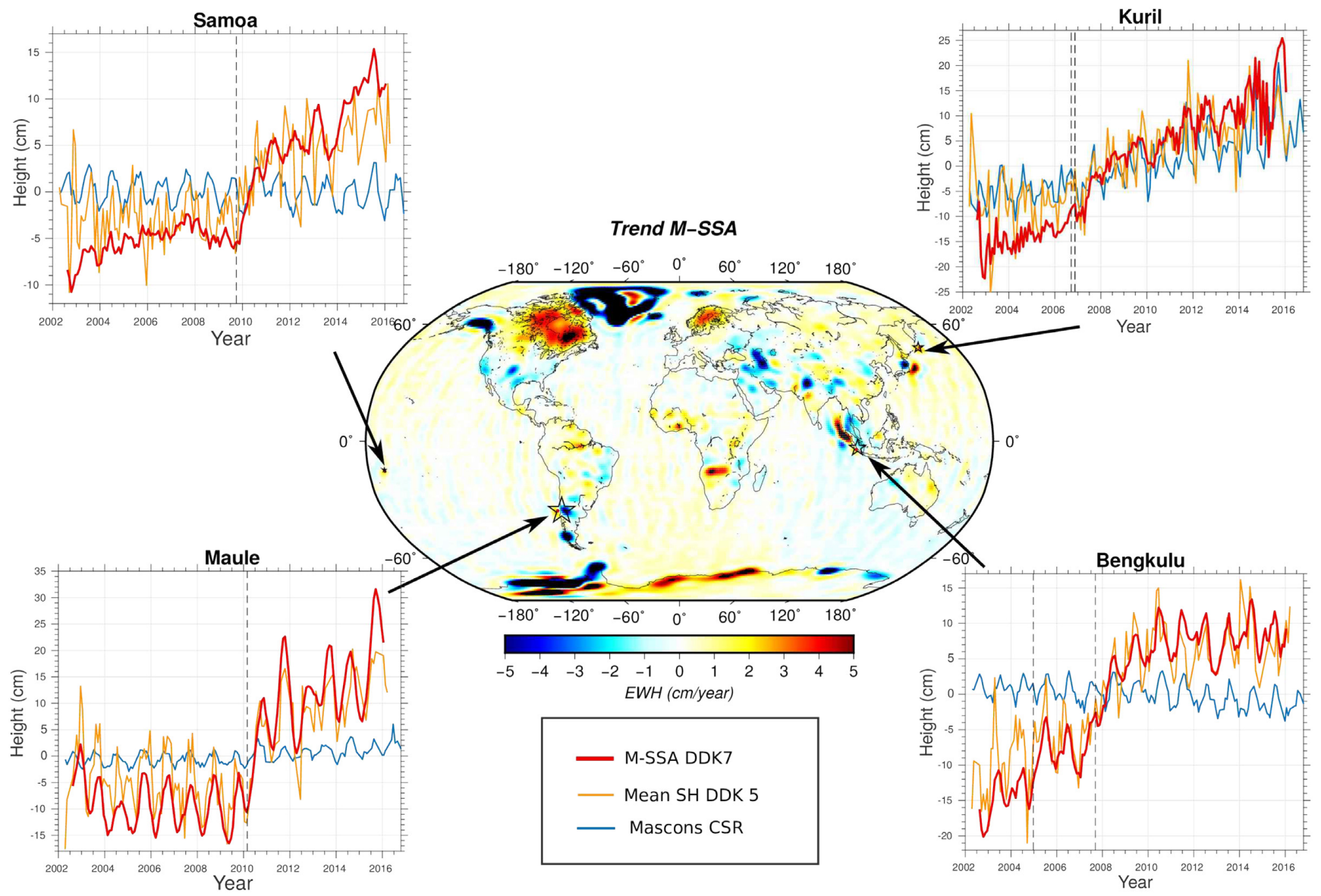

Figure 11. Surface mass density anomalies time-series, expressed as equivalent water height (EWH in cm), for the M-SSA, CSR mascon and mean SH-DDK5 GRACE solutions at the location of six recent major earthquakes. Their epicentres are indicated by open stars on the centre map, which also shows the January 2003-December 2014 EWH trend from the final M-SSA solution (in $\mathrm{cm} \mathrm{yr}^{-1}$ ). Note that the coseismic signals manifest themselves as jumps seen as positive or negative rates in the trend map.

\subsubsection{Co- and post-seismic gravity oceanic signals}

An application of GRACE data has been the quantification of co- and post-seismic gravity signals. This information complements displacement data from GNSS or InSAR measurements, for instance (e.g. Panet et al. 2007; Chen et al. 2007b; Han et al. 2010).

Here we compare the M-SSA solution with others before and after six recent major earthquakes: (1) the $M_{\mathrm{w}} 8.0$, 2009, Samoa outer-rise earthquake; (2) the $M_{\mathrm{w}} 8.8,2010$, Maule subduction earthquake off the Chilean coast; (3-4) the $M_{\mathrm{w}} 8.3,2006$ and $M_{\mathrm{w}} 8.1,2007$, Kuril Island subduction earthquakes and (5-6) the $M_{\mathrm{w}} 9,2004$, Sumatra and $M_{\mathrm{w}} 8.4,2007$, Bengkulu subduction earthquakes off the Sumatra shore; see Fig. 11 and Fig. S19.

The co- and post-seismic signals caused by these large events concern both the continental and oceanic areas that surround their epicentres. As mascon solutions, due to the employment of regularization strategies, tend to hamper the signal over the oceans (Fig. 9a), one does not expect them to be particularly reliable for the study of such events, for which they were not designed. Indeed, the CSR mascon solution in Fig. 11 shows no significant co- or post-seismic signal in any of the four regions, while the SH-based GRACE solutions show a clear coseismic offset, followed by an accelerated gravity change that is associated, in all likelihood, with the post-seismic deformation observed by GNSS.

The weakly pre-filtered, DDK7-based M-SSA solution also shows larger co- and post-seismic signals than the standard mean of the more strongly pre-filtered, DDK5-based SH solutions. This difference is most likely due to the degree of the DDK filter used. We conclude that the M-SSA solution preserves the co- and post-seismic signals in oceanic regions surrounding large subduction-related earthquakes as the official mean DDK5 solution does. Because of the lighter DDK7 filtering allowed by the M-SSA methodology described above, it is likely that the M-SSA solution better preserves the actual co- and post-seismic signals. A more thorough verification of this plausible conjecture requires, though, a complete earthquake model, which is beyond the scope of this study. 


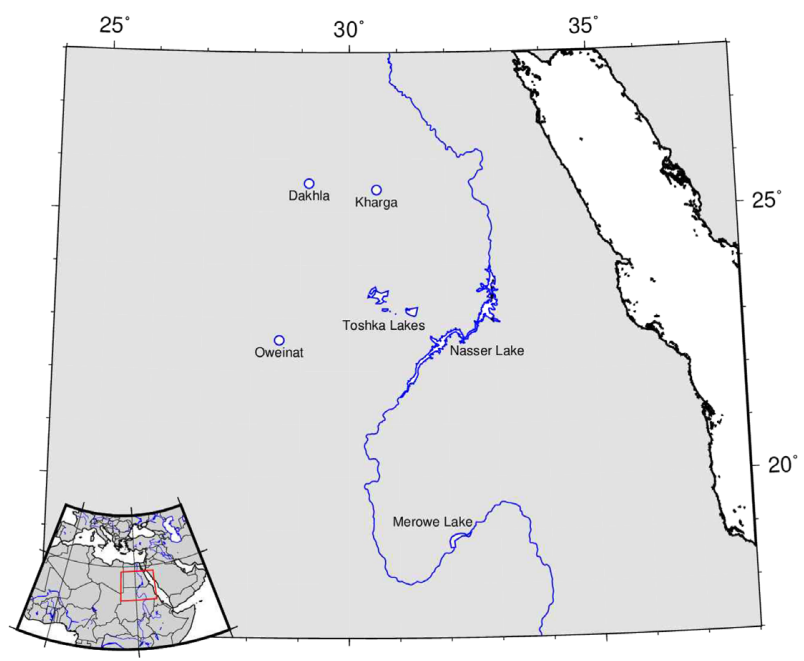

Figure 12. Localization map of the Nasser lake region.

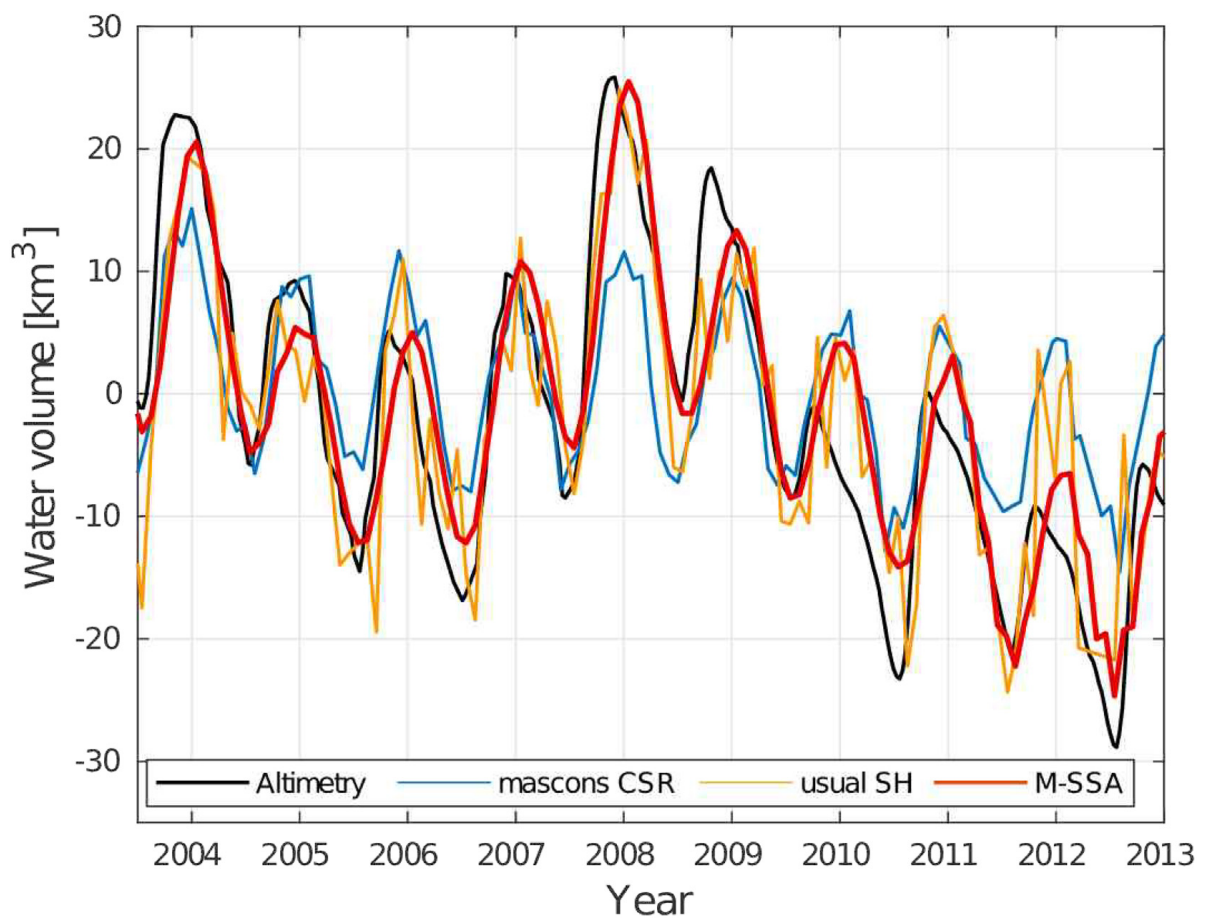

Figure 13. Time-series of the water volume (in $\mathrm{km}^{3}$ ) averaged over the Nasser lake area from four sources: in black the altimetry data, in blue the GRACE CSR mascon solution, in orange the usual GRACE spherical harmonics solution and in red the M-SSA GRACE solution.

\subsection{A comparison of the hydrologic fluctuations deduced from GRACE and from altimetric data: the Nasser lake area}

While the previous section is dedicated to an intercomparison of the gravity variations obtained after various treatments of the GRACE data, the present section attempts an intercomparison with respect to altimetry. Lake Nasser (Fig. 12) with an area close to $5200 \mathrm{~km}^{2}$ is not one of the largest lakes in the world. However, the time-series of water level deduced from altimetry are characterized not only by annual but also by pluriannual variations reaching peak to crest values over $8 \mathrm{~m}$ corresponding to water volume variations over $40 \mathrm{~km}^{3}$ (Fig. 13 ). Lake Nasser is situated in a desertic area where the hydrological perturbations in the surroundings are, as discussed below, relatively small so that they should not perturb considerably the comparison of water volumes deduced from altimetry and from GRACE. We present below both time-series between 2003 and 2013 (Fig. 13) deduced from altimetry and from various GRACE solutions and trend maps over the period comprised between January 2008 and December 2011 (Fig. 14). These trend maps illustrate how the various GRACE solutions quantify the water volume variation during one of the episodes of pluriannual variations of the Nasser lake water level.

The main source of hydrological fluctuations in the neighbourhood of lake Nasser is associated with the Toshka lakes (Fig. 12), west of Nasser lake, which serve as a spillway for Nasser lake. Fortunately the level and volume of water within Toshka lakes has been thoroughly quantified in a recent study (Chipman 2019) which indicates that the water volume of these lakes decreased by more than $20 \mathrm{~km}^{3}$ since 2002 . 

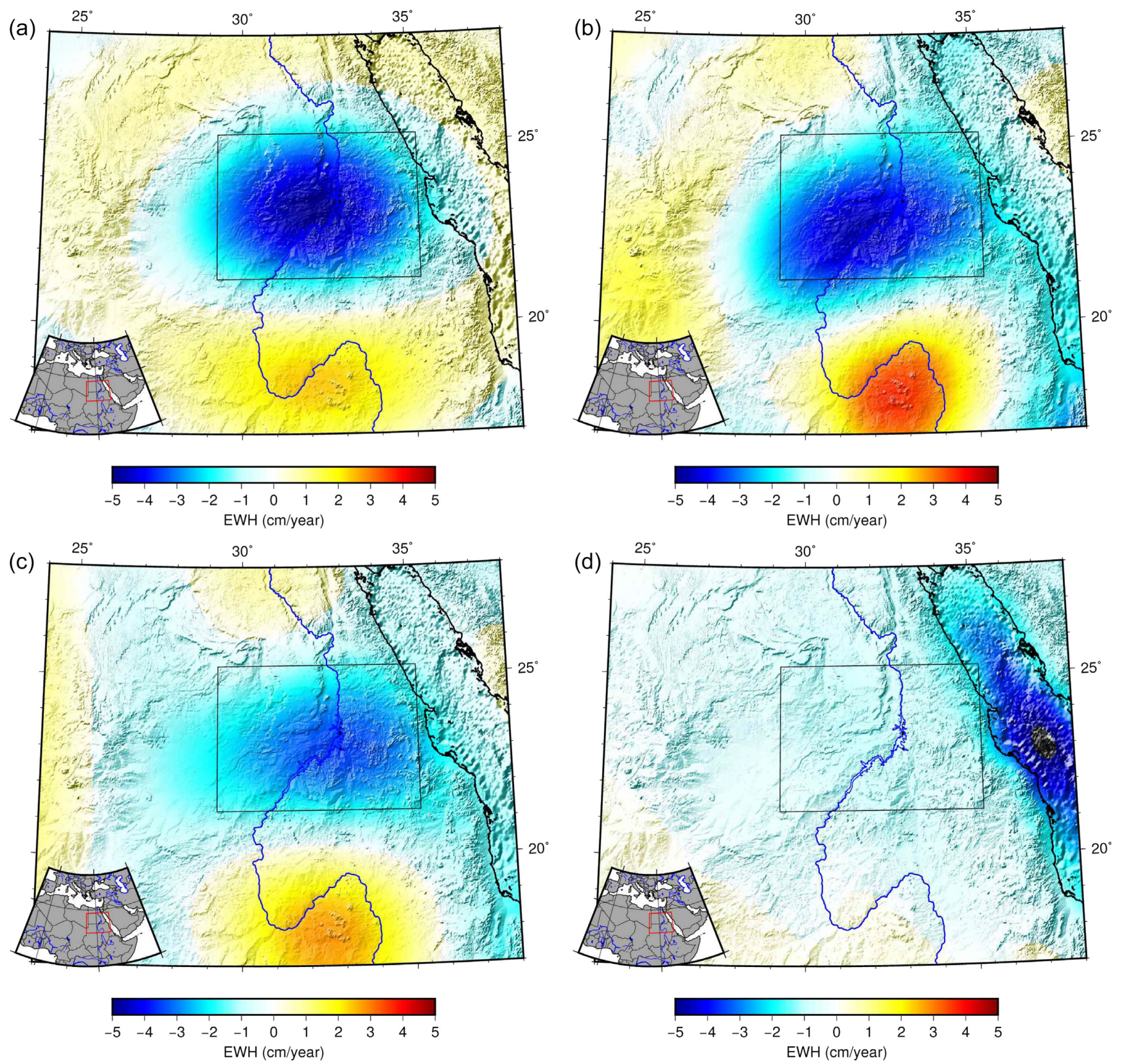

Figure 14. Surface mass density rates from January 2008 to December 2011 expressed in equivalent water height (EWH) per year (in $\mathrm{cm} \mathrm{yr}^{-1}$ ) for different solutions. (a) simulation adding various filtered sources (see 4.3 for details). (b) M-SSA GRACE solution. (c) The usual GRACE spherical harmonics solution. (d) The GRACE CSR mascon solution.

We will simply add in the area of Toshka lakes the volume of water proposed in Chipman (2019) to the water variations deduced from altimetry for Nasser lake in order to compute the altimetry time-series in Fig. 13 and the trend plotted in Fig. 14(a). In order to compute the water volume variations in Nasser lake, we use the relationship between water height and water volume proposed by Muala et al. (2014) (eq. 8) and based on a careful analysis of Landsat images. The water height has been deduced from the Hydroweb site http://hydroweb.theia-land.fr/hydroweb and is very close to that provided on the site https://ipad.fas.usda.gov/cropexplorer/global_reservoir. The Merowe dam has been built south of Nasser lake on the Nile and the reservoir, with a maximum capacity of $12.5 \mathrm{~km}^{3}$, has been empounded in 2009 . The subsequent fluctuations of water level within the lake are not known. We have added $12 \mathrm{~km}^{3}$ of water in the area of Merowe lake in our simulations of trends between 2008 and 2012 (Fig. 14a). We did not take it into account for the computation of the altimetry curve of Fig. 13 but Merowe lake is sufficiently far away from Nasser lake so that it would induce limited aliasing (a $1.5 \mathrm{~km}^{3}$ shift occurring in 2009) in the rectangle around lake Nasser area over which we average the water fluctuations.

West of the lake Nasser, there are several oases (see Fig. 12) which withdraw water stored more than $26000 \mathrm{yr}$ ago in the Nubian aquifer (Aly et al. 1993). The total withdrawal of water is of the order of is $1 \mathrm{~km}^{3} \mathrm{yr}^{-1}$ (Ebraheem et al. 2003). It is not known how the water gets afterward redistributed within the huge Nubian aquifer but little recharge seems to come from the southward part of the aquifer (Sultan 
et al. 2013). However, the amount of water withdrawn is sufficiently small that it should not affect considerably our predicted trends over 2008-2011 (assuming for example that half of the $1 \mathrm{~km}^{3} \mathrm{yr}^{-1}$ withdrawn water appears as an aliasing effect in the rectangle where we compute the time-series of Fig. 13, it would only induce a perturbation in the trend of $0.5 \mathrm{~km}^{3} \mathrm{yr}^{-1}$ versus the $7 \mathrm{~km}^{3} \mathrm{yr}^{-1}$ observed. Estimated seepage is rather limited for Nasser lake, less than $0.05 \mathrm{~km}^{3} \mathrm{yr}^{-1}$ (Hamdan et al. 2015).

Fig. 13 compares the time-series in $\mathrm{km}^{3} \mathrm{yr}^{-1}$ representing the water volume in the Nasser plus Toshka lakes [from altimetry and Chipman (2019)] with the water volume variation in the rectangle drawn in Fig. 14 according to various GRACE models. The CSR-mascon GRACE data set contains almost no pluriannual component while the mean of three centres (usual SH) and M-SSA GRACE data sets reproduce the pluriannual fluctuations of the altimetry curve. To be more quantitative, the trend between January 2008 and December 2011 of the four curves are $-7.8,-7.2,-6$ and $-2.3 \mathrm{~km}^{3} \mathrm{yr}^{-1}$ for, respectively, the altimetry, M-SSA, usual SH and mascon-CSR data sets. Note that the M-SSA and mean solutions have roughly the same pluriannual behaviour but with a lot of noise remaining in the usual SH solution.

In Fig. 14(a), we represent spatially filtered water volume trends over 2008-2011 obtained from the addition of altimetric trend over lake Nasser, volume variations over Toshka lakes from Chipman (2019) and with a $12 \mathrm{~km}^{3}$ water variation over Merowe lake. The spatial filter corresponds to that represented in Fig. S7(c) and is rather close to a DDK7 filter. The resulting spatially filtered trend is plotted in Fig. 14(a). It compares rather well in pattern and amplitude with Fig. 14(b) which depicts the trends for the M-SSA GRACE solution. The trend deduced from the usual SH GRACE solution (Fig. 14c) also exhibits a well marked minimum over Nasser lake as well as a maximum over Merowe lake. The elongated north-south negative stripe between longitudes $26^{\circ}$ and $28^{\circ}$ on Fig. 14(c) might be representative of spurious stripes not filtered out in the usual-SH solution. In contrast with the M-SSA and usual mean GRACE data sets, the mascon trends exhibit either no well localized minimum over Nasser lake (Figs 14d - CSR and S20a - JPL) or a weaker minimum (Fig S20b - GSFC) . The pluriannual water fluctuations of lake Nasser are rather well tracked in the raw spherical harmonic solutions and in the M-SSA solution but are strongly hampered in the mascon solutions.

\section{CONCLUSION}

We described in this paper a new method for filtering GRACE EWH data with minimum constraints on the $a$ priori spatial or temporal evolution of the gravity signal. The method is based on Multichannel Singular Spectrum Analysis (M-SSA), which we used at two levels. First, we used it to average the GRACE SH-based solutions from several analysis centres so that their common modes of variability were preserved, while their differences were filtered out. Secondly, we took advantage of the spatial and temporal correlations of gravity changes to design a simple M-SSA-based data-adaptive filter that efficiently removes the well-known residual north-south stripes present in all SH-based GRACE solutions. Using M-SSA as a data-adaptive filter allows us to use the noisier DDK7 product as a starting point for the analysis, which should help preserve the shape and magnitude of the actual geophysical signals as compared with the smoother, commonly used, DDK5 product.

We studied examples of large continental hydrological signals in and near the Caspian and Aral Seas to show that the SH-based M-SSA method recovers EWH changes as good as, or better than, the standard—filtered and averaged—SH-based or more recent mascon-based solutions. In this region of large recent EWH changes, the M-SSA solution shows signals that are more localized and of larger magnitude than other solutions. For example, the M-SSA solution identifies an area of irrigation-related water mass increase in northern Turkmenistan that was probably hampered by the noise of the standard SH solution and by the mascon solution's regularization. We also showed that the oceanic gravity signal due to large subduction-related earthquakes is well preserved by the M-SSA solution.

The M-SSA solution described here still requires spectrally filtered products from the analysis centres, but removes north-south residual stripes more effectively than the standard mean of SH-based, DDK5-filtered solutions.

The M-SSA methodology introduced herein could be easily applied in operational routine to the forthcoming new releases of GRACE data and future GRACE-FO data sets. The M-SSA solution remains somewhat noisier than the mascon solutions, but it is more accurate in areas where the hydrological signal is not well known and certainly in oceanic areas. As a consequence, the M-SSA solution may also serve as a guide for designing mascon regularization grids.

\section{ACKNOWLEDGEMENTS}

This work takes benefits of GRACE data processed by the Centre for Space Research (CSR) of the University of Texas (ftp://podaac.jpl.nasa. gov/allData/grace/L2/CSR/RL05/), the Institute of Geodesy of the University of Graz (GRAZ) (ftp:/ftp.tugraz.at/outgoing/ITSG/GRACE/IT SG-Grace2016/monthly/monthly_n120/), the German Research Centre for Geosciences (GFZ) (ftp://isdcftp.gfz-potsdam.de/grace/Level-2/G FZ/RL05/), the Jet Propulsion Laboratory (JPL) (ftp://podaac.jpl.nasa.gov/allData/grace/L2/JPL/RL05.1/), and the French Research Group for Space Geodesy (GRGS) (https://grace.obs-mip.fr/variable-models-grace-lageos/grace-solutions-release-03/). This study was funded by CNES-TOSCA grant 2925. Eric Calais acknowledges funding from the Institut Universitaire de France. Paoline Prevost acknowledges funding from the CNES doctoral program and from the University of Luxembourg. Kristel Chanard acknowledges IPGP contribution 4012. We thank C. Gruber and two anonymous reviewers for their thorough and constructive reviews which helped improving this paper. 


\section{REFERENCES}

Adhikari, S. \& Ivins, E.R., 2016. Climate-driven polar motion: 2003-2015, Sci. Adv., 2(4), e1501693-00.

Alessio, S.M., 2016. Digital Signal Processing and Spectral Analysis for Scientists: Concepts and Applications, Springer.

Aly, A., Froehlich, K., Nada, A., Awad, M., Hamza, M. \& Salem, W., 1993. Study of environmental isotope distribution in the Aswan High Dam Lake (Egypt) for estimation of evaporation of lake water and its recharge to adjacent groundwater, Environ. Geochem. Health, 15(1), 37-49.

Beaudoing, H. \& Rodell, M., 2016. Gldas Noah Land Surface Model L4 monthly $1.0 \times 1.0$ degree V2.1, Goddard Earth Sciences Data and Information Services Center (GES DISC).

Bettadpur, S., 2012. Insights into the Earth System mass variability from CSR-RL05 GRACE gravity fields, in EGU General Assembly Conference Abstracts, Vol. 14, p. 6409.

Cazenave, A. \& Chen, J., 2010. Time-variable gravity from space and present-day mass redistribution in the Earth system, Earth planet. Sci. Lett., 298(3-4), 263-274.

Chambers, D. \& Bonin, J., 2012. Evaluation of Release-05 GRACE timevariable gravity coefficients over the ocean, Ocean Sci., 8(5), 859-868.

Chen, J., Wilson, C., Famiglietti, J. \& Rodell, M., 2007a. Attenuation effect on seasonal basin-scale water storage changes from GRACE time-variable gravity, J. Geod., 81(4), 237-245.

Chen, J., Wilson, C., Tapley, B. \& Grand, S., 2007b. GRACE detects coseismic and postseismic deformation from the Sumatra-Andaman earthquake, Geophys. Res. Lett., 34(13), doi:10.1029/2007GL030356.

Chen, J., Wilson, C., Tapley, B., Save, H. \& Cretaux, J.-F., 2017. Long-term and seasonal Caspian Sea level change from satellite gravity and altimeter measurements, J. geophys. Res.: Solid Earth, 122(3), 2274-2290.

Chipman, J.W., 2019. A multisensor approach to satellite monitoring of trends in lake area, water level, and volume, Remote Sens., 11(2), 158.

Crétaux, J.-F., Kouraev, A.V., Papa, F., Bergé-Nguyen, M., Cazenave, A., Aladin, N. \& Plotnikov, I.S., 2005. Evolution of sea level of the big Aral Sea from satellite altimetry and its implications for water balance, J. Great Lakes Res., 31(4), 520-534.

Dahle, C., Flechtner, F., Gruber, C., König, D., König, R., Michalak, G. \& Neumayer, K., 2013. GFZ GRACE level-2 processing standards document for level-2 product release 0005: Revised edition, GeoForschungsZentrum, Potsdam.

Dee, D.P. et al., 2011. The ERA-Interim reanalysis: configuration and performance of the data assimilation system, Quart. J. R. Meteorol. Soc., 137(656), 553-597.

Ebraheem, A., Garamoon, H., Riad, S., Wycisk, P. \& El Nasr, A.S., 2003. Numerical modeling of groundwater resource management options in the East Oweinat area, SW Egypt, Environ. Geol., 44(4), 433-447.

Esenov, P.E., 2013. Groundwaters and salinization of soils in Turkmenistan, in The Turkmen Lake Altyn Asyr and Water Resources in Turkmenistan, pp. 141-150, Springer.

Flechtner, F., Dobslaw, H. \& Fagiolini, E., 2013. AOD1B product description document for product release 05, GFZ German Research Centre for Geosciences.

Flechtner, F., Neumayer, K.-H., Dahle, C., Dobslaw, H., Fagiolini, E., Raimondo, J.-C. \& Güntner, A., 2016. What can be expected from the GRACE-FO laser ranging interferometer for Earth science applications?, in Remote Sensing and Water Resources, pp. 263-280, Springer.

Forootan, E., Awange, J., Kusche, J., Heck, B. \& Eicker, A., 2012. Independent patterns of water mass anomalies over Australia from satellite data and models, Remote Sens. Environ., 124, 427-443.

Frappart, F., Ramillien, G., Maisongrande, P. \& Bonnet, M.-P., 2010. Denoising satellite gravity signals by independent component analysis, IEEE Geosci. Remote Sens. Lett., 7(3), 421-425.

Gaybullaev, B., Chen, S.-C. \& Gaybullaev, D., 2012. Changes in water volume of the Aral Sea after 1960, Appl. Water Sci., 2(4), 285-291.

Ghil, M. \& Vautard, R., 1991. Interdecadal oscillations and the warming trend in global temperature time series, Nature, 350(6316), 324.

Ghil, M. et al., 2002. Advanced spectral methods for climatic time series, Rev. Geophys., 40(1), 3.1-3.41.
Guo, J.Y., Duan, X.J. \& Shum, C.K., 2010. Non-isotropic Gaussian smoothing and leakage reduction for determining mass changes over land and ocean using GRACE data, J. geophys. Int., 181(1), 290-302.

Hamdan, A., Selim, S. \& Zaki, M., 2015. Estimation of Seepage Loss from Nasser Lake to the Adjacent Nubian Sandstone Aquifer, Southern Egypt, Int. J. Sci. Res., 4(9), 1106-1116.

Han, S.-C., Jekeli, C. \& Shum, C., 2004. Time-variable aliasing effects of ocean tides, atmosphere, and continental water mass on monthly mean GRACE gravity field, J. geophys. Res.: Solid Earth, 109(B4), doi:10.1029/2003JB002501.

Han, S.-C., Sauber, J. \& Luthcke, S., 2010. Regional gravity decrease after the 2010 Maule (Chile) earthquake indicates large-scale mass redistribution, Geophys. Res. Lett., 37(23), doi:10.1029/2010GL045449.

Jekeli, C., 1981. Alternative methods to smooth the Earth's gravity field, Reports of the Department of Geodetic Science and Surveying, Report No. 327, The Ohio State University, Columbus, OH, USA.

Kaplin, P.A. \& Selivanov, A.O., 1995. Recent coastal evolution of the Caspian Sea as a natural model for coastal responses to the possible acceleration of global sea-level rise, Mar. Geol., 124(1-4), 161-175.

Kondrashov, D. \& Ghil, M., 2006. Spatio-temporal filling of missing points in geophysical data sets, Nonlin. Process. Geophys., 13(2), 151-159.

Kondrashov, D., Feliks, Y. \& Ghil, M., 2005. Oscillatory modes of extended Nile River records (AD 622-1922), Geophys. Res. Lett., 32(10), doi:10.1029/2004GL022156.

Kusche, J., 2007. Approximate decorrelation and non-isotropic smoothing of time-variable GRACE-type gravity field models, J. Geod., 81(11), 733-749.

Kusche, J., Schmidt, R., Petrovic, S. \& Rietbroek, R., 2009. Decorrelated GRACE time-variable gravity solutions by GFZ, and their validation using a hydrological model, J. Geod., 83(10), 903-913.

Landerer, F.W. \& Swenson, S., , 2012. Accuracy of scaled GRACE terrestrial water storage estimates, Water Resour. Res., 48(4), doi:10.1029/2011WR011453.

Landerer, F.W., Dickey, J.O. \& Guentner, A., 2010. Terrestrial water budget of the Eurasian pan-Arctic from GRACE satellite measurements during 2003-2009, J. geophys. Res.-Atmos., 115( D23), doi:10.1029/2010JD014584.

Lemoine, J.-M., Bruinsma, S., Loyer, S., Biancale, R., Marty, J.-C., Perosanz, F. \& Balmino, G., 2007. Temporal gravity field models inferred from GRACE data, Adv. Space Res., 39(10), 1620-1629.

Lemoine, J.-M., Bruinsma, S., Gégout, P., Biancale, R. \& Bourgogne, S., 2013. Release 3 of the GRACE gravity solutions from CNES/GRGS, in EGU General Assembly Conference Abstracts, 15.

Luthcke, S.B., Sabaka, T., Loomis, B., Arendt, A., McCarthy, J. \& Camp, J., 2013. Antarctica, Greenland and Gulf of Alaska land-ice evolution from an iterated GRACE global mascon solution, J. Glaciol., 59(216), 613-631.

Lyard, F., 2010. T-UGOm (Toulouse-Unstructured Grid Ocean model), Developer manuals series.

Mayer-Gürr, T., Behzadpour, S., Ellmer, M., Kvas, A., Klinger, B. \& Zehentner, N., 2016. ITSG-Grace2016 - Monthly and Daily Gravity Field Solutions from GRACE.

Micklin, P., 2007. The Aral sea disaster, Annu. Rev. Earth Planet. Sci., 35, 47-72.

Moradi, A., Metivier, L., de Viron, O., Calmant, S. \& Mering, C., 2014. Evaluation of MODIS data for improved monitoring of the Caspian Sea, Int. J. Rem. Sens., 35(16), 6060-6075.

Muala, E., Mohamed, Y., Duan, Z. \& van der Zaag, P., 2014. Estimation of reservoir discharges from Lake Nasser and Roseires Reservoir in the Nile Basin using satellite altimetry and imagery data, Rem. Sens., 6(8), $7522-7545$

Opp, C., Groll, M., Aslanov, I., Lotz, T. \& Vereshagina, N., 2017. Aeolian dust deposition in the southern Aral Sea region (Uzbekistan): Groundbased monitoring results from the LUCA project, Quater. Int., 429, 86-99.

Panet, I. et al., 2007. Coseismic and post-seismic signatures of the Sumatra 2004 December and 2005 March earthquakes in GRACE satellite gravity, J. geophys. Int., 171(1), 177-190. 
Pyagay, E.T., 2012. Forecast of the water-salt balance in the Turkmen Lake Altyn Asyr, in The Turkmen Lake Altyn Asyr and Water Resources in Turkmenistan, pp. 151-157, Springer.

Ramillien, G., Famiglietti, J.S. \& Wahr, J., 2008. Detection of continental hydrology and glaciology signals from grace: a review, Surv. Geophys., 29(4-5), 361-374.

Rangelova, E., Sideris, M. \& Kim, J., 2012. On the capabilities of the multichannel singular spectrum method for extracting the main periodic and non-periodic variability from weekly GRACE data, J. Geodyn., 54, 64-78.

Rodell, M. et al., 2004. The global land data assimilation system, Bull. Am. Meteorol. Soc., 85(3), 381-394.

Rodell, M., Velicogna, I. \& Famiglietti, J.S., 2009. Satellite-based estimates of groundwater depletion in India, Nature, 460(7258), 999.

Saiko, T.A. \& Zonn, I.S., 2000. Irrigation expansion and dynamics of desertification in the Circum-Aral region of Central Asia, Appl. Geography, 20(4), 349-367.

Sakumura, C., Bettadpur, S. \& Bruinsma, S., 2014. Ensemble prediction and intercomparison analysis of GRACE time-variable gravity field models, Geophys. Res. Lett., 41(5), 1389-1397.

Save, H., Bettadpur, S. \& Tapley, B.D., 2016. High-resolution CSR GRACE RL05 mascons, J. geophys. Res.: Solid Earth, 121(10), 7547-7569.

Schrama, E.J., Wouters, B. \& Lavallée, D.A., 2007. Signal and noise in Gravity Recovery and Climate Experiment (GRACE) observed surface mass variations, J. geophys. Res.: Solid Earth, 112(B8), doi: 10.1029/2006JB004882.

Seo, K.-W., Wilson, C., Famiglietti, J., Chen, J. \& Rodell, M., 2006. Terrestrial water mass load changes from Gravity Recovery and Climate Experiment (GRACE), Water Resour. Res., 42(5), doi:10.1029/2005WR004255.

Seo, K.-W., Wilson, C.R., Chen, J. \& Waliser, D.E., 2008. GRACE's spatial aliasing error, J. geophys. Int., 172(1), 41-48.

Seoane, L., Ramillien, G., Frappart, F. \& Leblanc, M., 2013. Regional GRACE-based estimates of water mass variations over Australia: validation and interpretation, Hydrol. Earth Syst. Sci., 17, 4925-4939.

Shi, W. \& Wang, M., 2015. Decadal changes of water properties in the Aral Sea observed by Modis-Aqua, J. geophys. Res.: Oceans, 120(7), 4687-4708.

Shi, W., Wang, M. \& Guo, W., 2014. Long-term hydrological changes of the Aral Sea observed by satellites, J. geophys. Res.: Oceans, 119(6), 3313-3326.

Sultan, M. et al., 2013. 5.20 - assessment of the vulnerabilities of the Nubian Sandstone Fossil Aquifer, North Africa, in Climate Vulnerability, pp. 311-333, ed., Pielke, R.A., Academic Press, Oxford.

Swenson, S. \& Wahr, J., 2002. Methods for inferring regional surface-mass anomalies from Gravity Recovery and Climate Experiment (GRACE) measurements of time-variable gravity, J. geophys. Res.: Solid Earth, 107(B9), ETG 3-1-ETG 3-13.

Swenson, S. \& Wahr, J., 2006. Postprocessing removal of correlated errors in GRACE data, Geophys. Res. Lett., 33(8), doi:10.1029/2005GL025285.

Swenson, S. \& Wahr, J., 2007. Multi-sensor analysis of water storage variations of the Caspian Sea, Geophys. Res. Lett., 34(16), doi:10.1029/2007GL030733.

Tapley, B.D., Bettadpur, S., Watkins, M. \& Reigber, C., 2004. The gravity recovery and climate experiment: mission overview and early results, Geophys. Res. Lett., 31(9), doi:10.1029/2004GL019920.

Thompson, P., Bettadpur, S. \& Tapley, B., 2004. Impact of short period, nontidal, temporal mass variability on GRACE gravity estimates, Geophys. Res. Lett., 31(6).

Vautard, R. \& Ghil, M., 1989. Singular spectrum analysis in nonlinear dynamics with applications to paleoclimatic time series, Phys. D, 35, 395424.

Vautard, R., Yiou, P. \& Ghil, M., 1992. Singular-spectrum analysis: a toolkit for short, noisy chaotic signals, Phys. D: Nonlin. Phenom., 58(1-4), 95126.

Velicogna, I. \& Wahr, J., 2013. Time-variable gravity observations of ice sheet mass balance: precision and limitations of the GRACE satellite data, Geophys. Res. Lett., 40(12), 3055-3063.

Wahr, J., Molenaar, M. \& Bryan, F., 1998. Time variability of the Earth's gravity field: hydrological and oceanic effects and their possible detection using GRACE, J. geophys. Res.: Solid Earth, 103(B12), 30 205-30 229.

Walwer, D., Calais, E. \& Ghil, M., 2016. Data-adaptive detection of transient deformation in geodetic networks, J. geophys. Res.: Solid Earth, 121(3), 2129-2152.

Watkins, M.M. \& Yuan, D.-N., 2012. JPL Level-2 processing standards document for Level-2 product release 05, GRACE Document, 327-744.

Watkins, M.M., Wiese, D.N., Yuan, D.-N., Boening, C. \& Landerer, F.W., 2015. Improved methods for observing Earth's time variable mass distribution with GRACE using spherical cap mascons, J. geophys. Res.: Solid Earth, 120(4), 2648-2671.

Werth, S., Güntner, A., Schmidt, R. \& Kusche, J., 2009. Evaluation of GRACE filter tools from a hydrological perspective, J. geophys. Int., 179(3), 1499-1515.

Wouters, B. \& Schrama, E., 2007. Improved accuracy of GRACE gravity solutions through empirical orthogonal function filtering of spherical harmonics, Geophys. Res. Lett., 34(23), doi:10.1029/2007GL032098.

Zonn, I.S., 2012. Karakum canal: artificial river in a desert, in The Turkmen Lake Altyn Asyr and Water Resources in Turkmenistan, pp. 95-106, Springer.

\section{SUPPORTING INFORMATION}

Supplementary data are available at $G J I$ online.

Figure S1. Surface mass density anomalies solutions for January 2006 relative to July 2005, expressed in equivalent water height (EWH in $\mathrm{cm}$ ), derived from GRACE. (a) By CSR calculation centre and filtered with the decorrelation filter DDK5. (b) By GFZ calculation centre and filtered with DDK5. (c) By GRAZ calculation centre and filtered with DDK5. (d) By CNES/GRGS calculation centre. (e) By JPL calculation centre and filtered with DDK5.

Figure S2. Mean of JPL, GFZ and CSR surface mass density rates from 2003 to 2015 expressed in equivalent water height (EWH) per year (in $\mathrm{cm} \mathrm{yr}^{-1}$ ), derived from GRACE. (a) With the decorrelation filter DDK5. (b) With the decorrelation filter DDK7.

Figure S3. Multichannel singular spectrum analysis (M-SSA) step 1 decomposition of GRACE spherical harmonics. The first 4 panels show one or a visually made combination of partial reconstructions (RCs) of similar nature for each processing centre: CSR (blue), GFZ (red), yellow (GRAZ), CNES/GRGS (purple) and JPL (green). The bottom panel shows the signal reconstructions using the first 8 RCs for each of the 5 GRACE solutions and the mean of the reconstructions (black). (a) $S_{4.2}$. (b) $S_{20.5}$. (c) $S_{20.19}$. (d) $C_{50.35}$.

Figure S4. Surface mass density anomalies solutions for January 2006 relative to July 2005, expressed in equivalent water height (EWH, in $\mathrm{cm})$. (a) the M-SSA GRACE step 1 solution obtained from the mean of all 5 processing centres' signals filtered with DDK7 and reconstructed from the leading 12 RCs of the M-SSA step 1; (b) the difference between the reconstructed signal with 12RCs and the one with 8RCs.

Figure S5. Standard deviation ratio of time dependent spherical harmonics $Y_{l m}(t)$ between (a) the mean of the five centres filtered with DDK7 and the mean of the raw ones; (b) MSSA filtered (step 1) and the mean of the DKK7 filtered ones; (c) MSSA (step 1) filtered and the mean 
of the raw ones; (d) MSSA (step 2) filtered and MSSA (step 1) filtered ones (in grey when $\left.\operatorname{var}\left(Y_{l m}(t)\right)<3 \times 10^{-3}\right)$; and (e) MSSA (step 2) filtered and the mean of the raw ones.

Figure S6. Multichannel singular spectrum analysis (M-SSA) step 2 decomposition of surface mass density anomalies time-series derived from GRACE. The first 3 or 4 panels show one or a visually made combinations of partial reconstructions (RCs) of similar nature. The bottom panel shows the time-series prior to the final M-SSA (blue) and the signal reconstructed using the first 8 RCs (red). (a) At latitude $40^{\circ} \mathrm{N}$ and longitude $20^{\circ}$ E. (b) At latitude $16^{\circ} \mathrm{S}$ and longitude $48^{\circ} \mathrm{W}$.

Figure S7. Standard deviation ratio of time dependent spherical harmonics coefficients $Y_{l m}(t)$ from GLDAS data between (a) the one filtered with DDK7 and the raw ones; (b) the M-SSA filtered and the DKK7 filtered ones (in grey when $\left.\operatorname{var}\left(Y_{l m}(t)\right)<3 \times 10^{-3}\right)$; (c) the M-SSA filtered and the raw ones.

Figure S8. Time-series of total water storage from GLDAS data before (blue) and after (red) the M-SSA with 8 RCs, and $\mathbf{r}$ the correlation coefficient between these time-series. (a) In Colorado at latitude $40^{\circ} \mathrm{N}$ and longitude $104^{\circ} \mathrm{W}$; (b) in Brazil at latitude $10^{\circ} \mathrm{S}$ and longitude $55^{\circ} \mathrm{W}$; (c) in Germany at latitude $50^{\circ} \mathrm{N}$ and longitude $10^{\circ} \mathrm{E}$; (d) in Hungary at latitude $47^{\circ} \mathrm{N}$ and longitude $19^{\circ} \mathrm{E}$; (e) in Nigeria at latitude $9^{\circ} \mathrm{N}$ and longitude $6^{\circ} \mathrm{E}$; (f) in Thailand at latitude $15^{\circ} \mathrm{N}$ and longitude $100^{\circ} \mathrm{E}$. In panel (a), the time serie after M-SSA but with $10 \mathrm{RCs}$ has been added (green curve).

Figure S9. (a) Surface mass density anomalies difference for January 2006 relative to July 2005, expressed in equivalent water height (EWH in $\mathrm{cm}$ ), between the mean of the JPL, GFZ and CSR solutions, each filtered with DDK7, and the M-SSA solution obtained herein after M-SSA step 2. (b) Same difference map as in panel (a) but the mean of the JPL, GFZ and CSR solutions is filtered with the stronger DDK5 filter.

Figure S10. (a) Surface mass density rates from 2003 to 2015 difference expressed in equivalent water height (EWH) per year (in $\mathrm{cm} \mathrm{yr}^{-1}$ ), between the mean of JPL, GFZ and CSR solutions filtered with the decorrelation filter DDK7 and the final M-SSA solution. (b) Same mass rates difference but the mean of JPL, GFZ and CSR solutions is filtered with the decorrelation filter DDK5.

Figure S11. Surface mass density anomalies difference for January 2006 relative to July 2005 expressed in equivalent water height (EWH in $\mathrm{cm}$ ), between one of the used common solutions filtered with the decorrelation filter DDK7 and the M-SSA solution: (a) solution from CSR; (b) solution from GFZ; (c) solution from GRAZ; (d) solution from GRGS and (e) solution from JPL.

Figure S12. M-SSA surface mass density anomalies solutions for January 2006 relative to July 2005, expressed in equivalent water height (EWH in $\mathrm{cm}$ ), after restoration of the ocean and atmospheric model over oceans (from AOD1B, ERA-Interim and TUGO) that is removed during the processing of GRACE spherical harmonics data. We need to add them back to compare the M-SSA solution to mascons solution that do not use this correction.

Figure S13. Mascons surface mass density anomalies solutions for January 2006 relative to July 2005, expressed in equivalent water height (EWH in cm). (a) JPL mascons solution. (b) Goddard mascons solution. And surface mass density anomalies differences for January 2006 relative to July 2005, expressed in equivalent water height (in $\mathrm{cm}$ ), between a mascons solution and the M-SSA solution. (c) JPL mascons. (d) Goddard mascons

Figure S14. Mascon surface mass density rates from 2003 to 2015 expressed in equivalent water height (EWH) per year (in $\mathrm{cm} \mathrm{yr}^{-1}$ ). (a) CSR mascons. (b) JPL mascons. (c) Goddard mascons.

Figure S15. Surface mass density rates from 2003 to 2015 difference expressed in equivalent water height (EWH) per year (in $\mathrm{cm} \mathrm{yr}^{-1}$ ) between a mascons solution and the M-SSA solution. (a) CSR mascons. (b) JPL mascons. (c) Goddard mascons.

Figure S16. Mascons surface mass density anomalies differences for January 2006 relative to July 2005, expressed in equivalent water height (EWH in $\mathrm{cm}$ ) between the mascons solution from CSR and (a) the mascons solution from JPL (b) the mascons solution from GFSC.

Figure S17. Surface mass density rates from 2003 to 2015 expressed in equivalent water height (EWH) per year (in $\mathrm{cm} \mathrm{yr}^{-1}$ ) in the Caspian Sea and surrounding regions. (a) JPL mascons. (b) Goddard mascons.

Figure S18. Surface mass density rates from 2003 to 2015 expressed in equivalent water height (EWH) per year (in $\mathrm{cm} \mathrm{yr}^{-1}$ ) of the M-SSA solution and surface mass density anomalies in EWH time-series at four places on Earth represented by the boxes on the map.

Figure S19. Surface mass density rates from 2003 to 2015 expressed in equivalent water height (EWH) per year (in $\mathrm{cm} \mathrm{yr}^{-1}$ ) of the M-SSA solution and surface mass density anomalies in EWH time-series at four places on Earth represented by the stars on the map. Co- and post-seismic signals linked to six major earthquakes can be seen on these time-series from M-SSA and usual spherical harmonics solutions. In the contrary, times-series from the three mascons solutions don't show any sign of seismic signal.

Figure S20. Surface mass density rates from January 2008 to December 2011 expressed in equivalent water height (EWH) per year (in

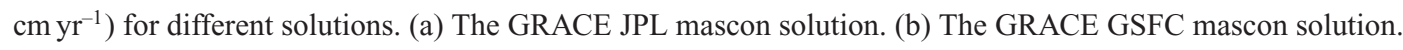

Please note: Oxford University Press is not responsible for the content or functionality of any supporting materials supplied by the authors. Any queries (other than missing material) should be directed to the corresponding author for the paper. 